\title{
Electric Two-Wheeler Vehicle Integration into Rural Off-grid- Photovoltaic System in Kenya
}

\author{
Aminu Bugaje ${ }^{1, *}$, Mathias Ehrenwirth ${ }^{1}$, Christoph Trinkl ${ }^{1}$, and Wilfried Zörner1 \\ 1 Institute of New Energy Systems, Technische Hochschule Ingolstadt, 85049, Germany; aminu.iliya- \\ subugaje@thi.de (A.B); mathias.ehrenwirth@thi.de (M.E.); christoph.trinkl@thi.de (C.T.); wilfried.zo- \\ erner@thi.de (W.Z.) \\ * Correspondence: aminu.iliyasubugaje@thi.de
}

\begin{abstract}
Two-wheeler vehicles are the most significant mode of transportation for Kenyans in both rural and urban regions thereby contributing to local air pollution, and greenhouse gas emissions (GHG). The transition to electric two-wheeler vehicles can make a significant contribution to reducing GHG and improving the socio-economic lives of people living in rural Kenya. Renewable energy systems can considerably contribute to the charging of electric two-wheeled vehicles, thus leading to the reduction of carbon emissions and the expansion of renewable energy penetration in rural Kenya. Therefore, this paper focuses on integrating and modelling electric two-wheeled vehicles (ebikes) into an off-grid photovoltaic Water-Energy Hub located in the Lake Victoria Region of Western Kenya using the Conventional and Renewable Energy Optimization (CARNOT) Toolbox in MATLAB / Simulink. Electricity demand data obtained from the Water-Energy Hub was investigated and analysed. Potential solar energy surplus was identified and electric two-wheeler vehicles were integrated based on the surplus. A field measurement investigation on the energy consumption of the electric two-wheeler vehicles based on the rider's driving behaviour was also carried. The annual electricity demand of $27,267 \mathrm{kWh}$, photovoltaic (PV) electricity production of 37,785 $\mathrm{kWh}$ with an electricity deficit of $370 \mathrm{kWh}$ were obtained from the simulation results. To reduce the electricity deficit, a load optimisation algorithm was developed to optimally integrate the electric 2wheeler vehicle into the Water-Energy Hub. It was found that using the load optimisation algorithm, the annual electricity deficit was reduced to $1 \mathrm{kWh}$ and the annual electricity demand was increased by $11 \%(30,767 \mathrm{kWh})$ which is enough to charge 4 additional electric two-wheeler batteries daily.
\end{abstract}

Keywords: Lake Victoria; Photovoltaic; off-grid; model; electric two-wheeled vehicle; Water-Energy Hub; CARNOT;

\section{Introduction}

To reduce carbon dioxide emissions, a global leapfrog to electric vehicles is already ongoing in countries like Norway, China, etc. Transportation accounts for about a quarter of all $\mathrm{CO}_{2}$ emissions from energy usage [1]. By 2050, when the global number of passenger cars is expected to more than double, it is likely to hit one-third. This rise is primarily anticipated in low-income countries, where vehicle emissions standards are rarely enforced [1].

Electric vehicles (EVs) have an efficiency of 80-95\% [2], which makes them a better alternative than conventional vehicles (CVs), which have an efficiency of less than $20 \%$ [3]. EVs are a crucial component of modern transportation because they include a range of innovative industrial technologies (e.g., an electric motor, a battery, and a charging facility). However, electric car adoption is not progressing as quickly as expected. The restricted range and long charging time of electric vehicles are often viewed as the most significant impediments to their adoption $[4,5]$. Despite their high purchase price, electric vehicles have low maintenance costs and use far less energy than conventional automobiles [6]. 
As the demand for power and electricity by EVs was rising rapidly, numerous research centers and energy supply businesses started seriously thinking about decreasing pressure on local electricity networks due to the increasing number of charging outlets for electric vehicles. The most efficient way of addressing this deficiency in the face of local electricity grids is to supply the EV charging infrastructure [7] with renewable energy sources (RES), like wind and solar.

RES can considerably contribute to the reduction of carbon emissions and the expansion of renewable energy penetration. However, the challenges of implementing RES are in its variabilities such as seasonal changes to wind and sunlight, and daily cloud randomness in solar power panel coverage [8]. Hence, proper design of solar PV systems is important to avoid oversizing or under-sizing the system, resulting in either excessive capital costs or insufficient solar electricity production [9].

Therefore, this paper presents the results of a modelled off-grid photovoltaic WaterEnergy Hub (WeTu Hub) that is implemented by Siemens Foundation through WeTu Ltd (i.e. its implementation partner) [10] around Lake Victoria. The WeTu Hub is used to provide reliable and clean electricity for charging fishing lanterns, other electric appliances, and batteries for electric 2-wheeler (e-bikes) for water and local transportation.

\section{Motivation}

More than $90 \%$ of Africa's transportation of goods and services is done by road which leads to a huge dependency on fossil fuels and contributes to greenhouse (GHG) emissions. This huge dependency on fuels mostly imported, pressurizes African governments to heavily subsidise fuels to protect consumers from ever-increasing oil prices. Despite this, consumers and vehicle drivers are often faced with huge cost burdens, fuel shortages leading to long hours of queuing for fuel [11, 12].

Moreover, SLoCaT [13] reports that global transport emissions had grown by $31 \%$ from 2000 to 2016 and Asia had the highest transport emission growth of $92 \%$ followed by Africa ( $84 \%)$, then Latin America (49\%) while they have been falling in Europe and North America. Transport emissions which are primarily driven by an increase in passenger and freight transport activity have increased by $75 \%$ in SSA from 2000 to 2016 to a level of 156 million tonnes (Mt) $\mathrm{CO}_{2}$. This $\mathrm{CO}_{2}$ transport emissions increase includes e.g., $161 \%$ in Algeria, 153 \% in Ghana, 123 \% in Kenya, 73 \% in Egypt, and 40 \% in South Africa.

Mbita is chosen for this study because it fits well to the criteria set for the selection of case study location (i.e., opportunities for short-range electrical vehicles). The transport business in Mbita is very vibrant and a significant source of income for the residents of Mbita. The motorcycle is the most important mode of transport in Mbita and is used to transport goods and people within short distances and to the town of Kisumu, which is the largest urban centre in the region [14].

However, from a general public welfare point of view, motorcycle transport presents clear disadvantages in terms of negative externalities such as pervasive noise, increased local air pollution, and greenhouse gas emissions [15]. Consequently, given that gasolinepowered motorcycles present huge economic and environmental challenges, the transition to electric motorcycles can make a significant contribution to improving the socioeconomic lives of people living in Mbita and around Lake Victoria by reducing fuel costs, $\mathrm{CO}_{2}$ emissions.

Therefore, this paper intends to optimally integrate e-bikes into an off-grid solarpowered Water-Energy Hub (WeTu Hub) around Lake Victoria in Western Kenya. The paper presents the analysis of the measured electricity consumption data of the WeTu Hub, a simulation model of the WeTu Hub using the CARNOT simulation toolbox in MATLAB / Simulink environment, identification of potential energy surplus for e-bikes integration. The paper also presents a measurement investigation on distance-related energy consumption of e-bikes in $\mathrm{kWh} / 100 \mathrm{~km}$. The e-bikes considered in this study were provided by WeTu Ltd through Siemens foundation and these comprise of e-OpiBus, e-BodaWerk, and Anywhere Berlin e-cargo bikes. 


\section{Reviews on optimal modelling and sizing of EV charging infrastructure}

The transition and penetration of EVs into the society have been made possible due to the investments in battery charging infrastructure. However, this increases the pressure on the conventional electricity distribution networks (CEDN). Therefore, the capacity of electricity distribution systems needs to be upgraded through the integration of RESs into the charging stations to reduce potential overload challenges. Moreover, it is the most demanding task to fulfill the expanding demands of EVs by optimising their charging infrastructure size and operation. Several studies to overcome the above difficulties have been documented and are presented in Table 1.

From Table 1, it can be seen that research on off-grid and on-grid PV systems used for electric vehicle charging had been conducted. This paper intends to adapt the work of [16] by integrating e-bikes (e-motorcycles and e-cargo) into a rural off-grid PV system. This paper will also present the optimal integration of the e-bikes using a load optimisation algorithm that utilises 7 days PV forecast which is missing in the work of [16]. 
Table 1. Summary of literature reviews on EV charging infrastructure.

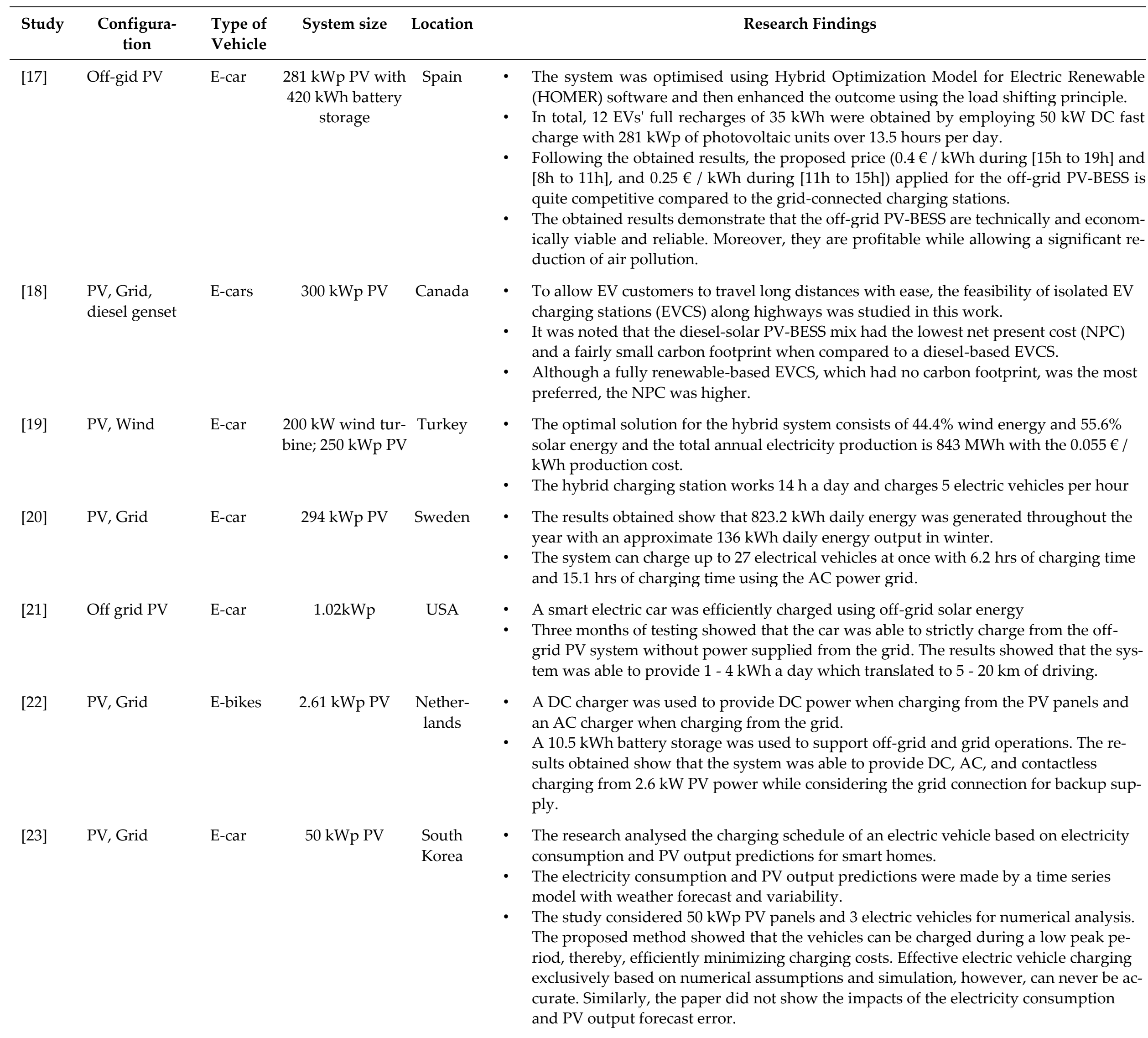


[24] PV, Grid E-cars

10 kWp PV lands

Microgrid-

PV,

Genset

Microgrid-

PV,

Genset

Standalone

PV- mini-grid

PV, Grid,

Wind,

Hydro

\section{PV, Grid}

E-car

\section{E-car}

7,497 kWp PV Rwanda

13 kWp PV; $51 \quad$ MalkVA Genset dives dives

(1)

- Grid, PV, V2G $10 \mathrm{~kW}$ solar-powered EV charger with V2G for workplaces in the Netherlands is analysed.

- $10 \mathrm{kWh}$ local storage reduced grid energy exchange by $25 \%$.

- It was proved that local battery storage does not eliminate the grid dependence of the EV - PV charger in the Netherlands, especially due to seasonal variations in insolation

- Energy management scheme for electric vehicle (EV) charging using photovoltaic (PV) and energy storage, connected to the microgrid was presented based on the heuristic rule-based strategies to optimize energy flow within a microgrid

- During the absence of PV power, the EV demand is fulfilled by the GenSet

- Using the PV as the main source for charging Evs, the burden on the microgrid is reduced significantly thereby becoming more economical compared to charging from the standalone generator.

- Integration of solar PV microgrids for the satisfaction of electric vehicle (EV) technology in Rwanda using HOMER.

- The outcome of the proposed research can lead to an efficient increase in national energy resource exploitation in Rwanda.

- Research explores the commercial viability of using electric vehicles (EVs), recharged by solar mini-grids, to provide transport services in off-grid communities in the Gambia using $4.5 \mathrm{kWp}$ of photovoltaic modules from the roof of a parking shelter for the vehicle.

- Results provide confidence that several modes of operation are possible in which solarrecharged electric taxis can be commercially viable in The Gambia. The most optimistic scenarios arise from the use of lightweight vehicles, such as tuk-tuks (autorickshaws) and cargo bikes.

- Explores the use of potential renewable electricity generation systems by local taxi services in Daejeon, using HOMER.

- Systems using solar energy, wind energy, batteries, converters, and the electrical grid are proposed for the third stage of the adoption of electric-powered taxis (EP taxis) in Daejeon, South Korea

- The uncertainty in producing electricity by renewable energy resources supports the economic feasibility and reliability of the proposed grid-connected system.

- Simulation results indicated that establishing renewable electricity generation systems with grid connections is a more optimal solution than independent renewable electricity generation systems. It may be economic to sell any surplus electricity and buy any insufficient electricity from the local grid when required.

- The researchers conducted a study on 6 electric scooters used by university students, which were charged by using a grid-connected PV system. The charging from the PV system was obtained when the PV system generated enough energy to charge the electric scooters, otherwise charging from the grid was obtained.

- The field results showed that $94.3 \%$ direct charging from the $3 \mathrm{kWp}$ PV system and 5.7 $\%$ charging from the grid were obtained during the summer period and a higher percentage of grid charging during winter. The grid charging during winter periods makes the research not fully eco-friendly because a big extent of grid power was generated from fossil fuels. 


\section{About the Water-Energy Hub}

WeTu Ltd owns the Water-Energy Hubs (WeTu Hub), an off-grid PV-powered energy hub that allows Kenyans in remote areas surrounding Lake Victoria to have access to sustainably generated electricity [10, 29]. The WeTu Hub (see

Figure 1 top) are self-contained PV systems (about $30 \mathrm{kWp}$ ) in which the power generated is temporarily stored in appropriate battery storage systems (capacity roughly 104 $\mathrm{kWh}$ ) and made available to the on-site residents. In addition to traditional usage (such as charging fishing lights), electricity is utilised to purify drinking water (see Table 2 and

Figure 1, bottom) and therefore contributes positively to the environment.

Table 3 show the detailed information of the electricity generation and major electricity consumers at Mbita $\mathrm{WeTu} \mathrm{Hub}$ respectively.
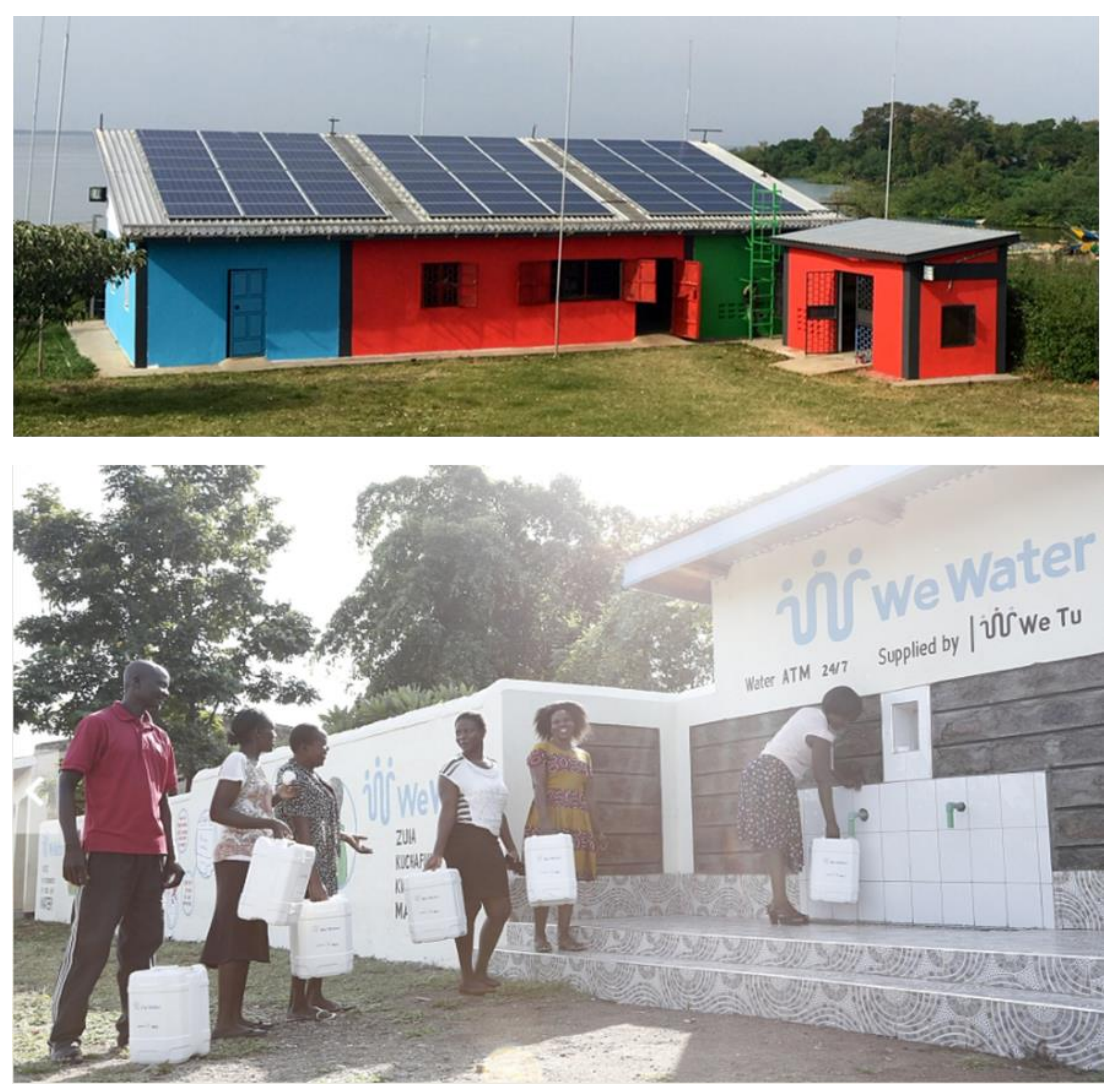

Figure 1. Location of the case study area - Mbita, Kenya (Lake Victoria) [29]

Table 2. Detailed information on electricity generation at Mbita WeTu Hub [30-36].

\begin{tabular}{cc}
\hline System Components & System Specifications \\
\hline PV Modules & Bosch Solar c-Si-M60-M240-3BB (240W) \\
PV Module Quantity & 126 \\
PV Module Power Rating & $30.24 \mathrm{kWp}$ \\
PV Inverters & STP15000TL-30 (SMA Sunny Tripower 15kVA) \\
PV Inverter Rating & $30 \mathrm{kVA}$ \\
Batteries & $104 \mathrm{kWh}$ \\
\hline
\end{tabular}


Table 3. Detailed information on major electricity consumers at Mbita WeTu Hub [37].

\begin{tabular}{ccc}
\hline Major Electricity Consumers & Power Rating $(\mathbf{W})$ & Number \\
\hline Fishing Lanterns & 105 & 200 \\
Water Purifier & 120 & 1 \\
Floodlight & 40 & 1 \\
CFL Light Bulbs & 8 & 7 \\
Fluorescent & 18 & 2 \\
Computer & 150 & 2 \\
\hline
\end{tabular}

\section{Methodology}

The methodology of this paper is divided into four sections; 1 ) Analysis of the WeTu $H u b, 2)$ Measurement investigation on e-bikes, 3) Integration of e-bikes into WeTu Hub, 4) Development of a load management algorithm. Figure 2 shows the proposed methodology of this paper.

To analyse the WeTu Hub, measurement data between August 2020 and December 2020 of electricity consumption at the $H u b$ was evaluated. Workdays, weekends during non-moon phases, and moon phases based on the lunar calendar [38] for the year 2020 were identified from the measurement data. A synthetic load profile was generated using the identified workdays and weekends load profiles. This resulted in the generation of an annual load profile using MATLAB and was fed into a simulation model of the WeTu Hub. A historic annual weather data of Mbita (with one-hour resolution) obtained from Meteonorm [39] was also fed into the simulation model. Energy surplus was identified for ebikes integration.

To determine the potential number of battery swaps a rider might require per day / $100 \mathrm{~km}$, a field measurement investigation was carried out on the e-bikes by MOI university and WeTu Ltd engineers [10] considering factors such as trip distance, speed, payload weight. The outcome of the measurement was used to determine the distance-related energy consumption of the e-bikes in $\mathrm{kWh} / 100 \mathrm{~km}$.

To integrate the e-bikes into the WeTu Hub, a daily and annual load profile for the ebikes was generated and integrated into the existing WeTu Hub's load profile using the outcome of the measurement investigation. Charging time, charging rate, battery capacity, etc. from the measurement investigation aided in the load profile generation for the individual type of bikes.

To optimise the load profile for optimum integration of the e-bikes into the WeTu $H u b$, a load management algorithm was developed using Non-linear programming (NLP). The generated hourly resolution simulation results such as annual PV electricity production, battery supply, battery state of charge (SoC), and electricity deficit were analysed. 


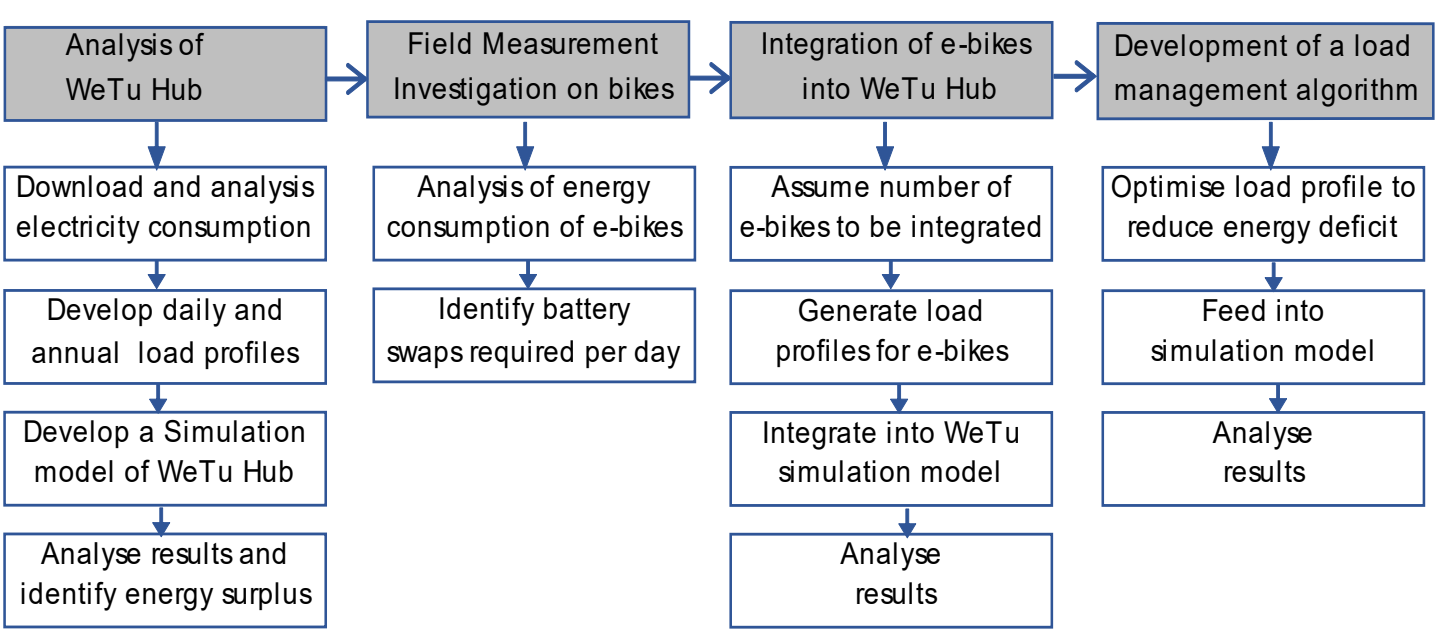

Figure 2. Proposed methodology.

\section{Analysis of electricity data from $\mathrm{WeTu} \mathrm{Hub}$}

Electricity consumption during night and day was measured using the SMA data manager that was installed at Mbita WeTu Hub. A carpet plot (see Figure 3) of the electricity consumption was generated to help understand the energy usage at the Mbita WeTu $\mathrm{Hub}$ and generate the future load profiles of the e-bikes. The existing loads that constitute the carpet plot for the WeTu Hub electricity consumption can be seen in Table 2

Table 3. It can be seen in Figure 3 that the normal operating period at the WeTu Hub was between August and October, while field measurement on e-bikes was between October - December. The least electricity demand was recorded in December due to partial lockdown to reduce Christmas activities.

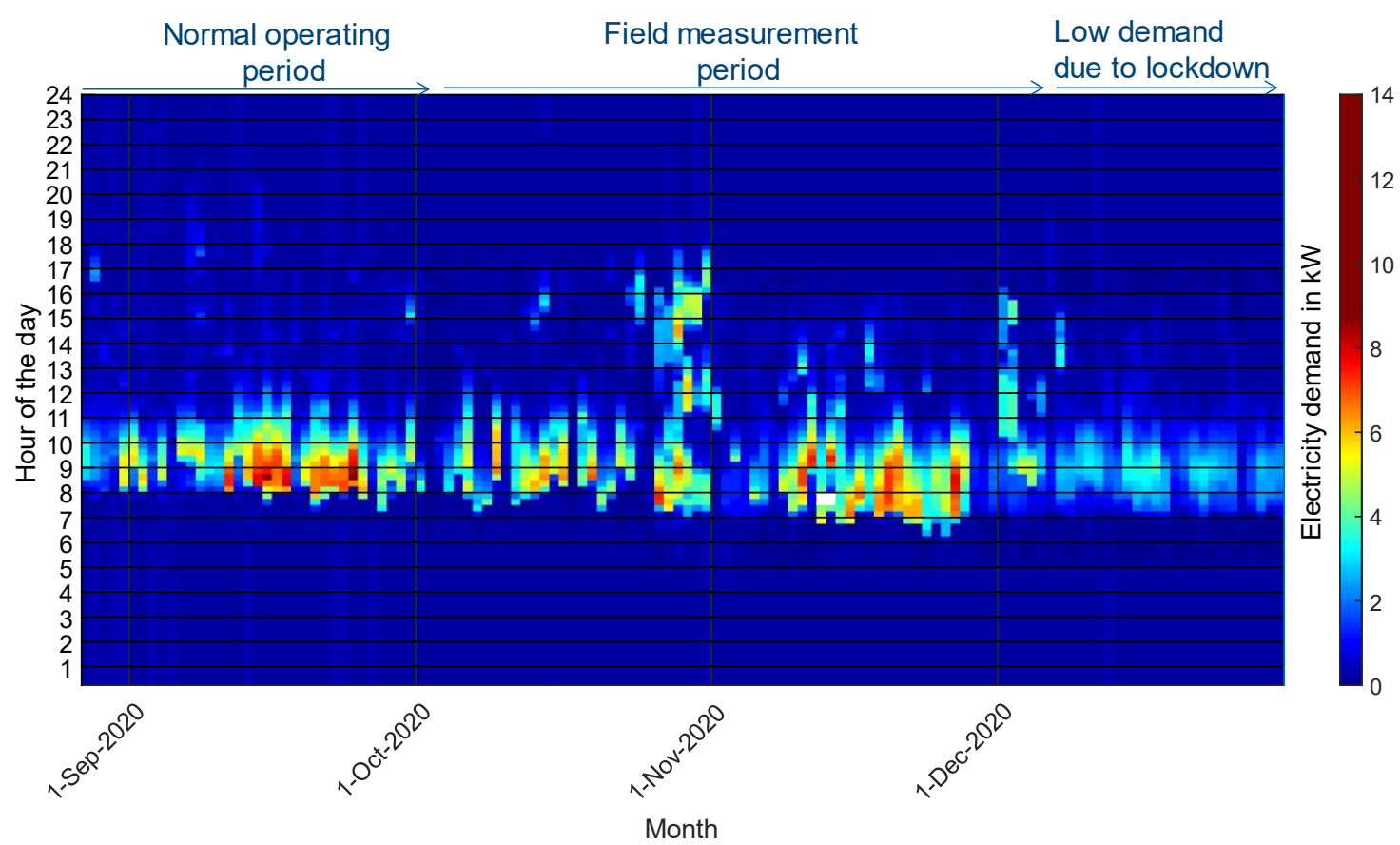

Figure 3. Carpet plot of measured electricity consumption data from Mbita WeTu Hub.

6. 1 Analysis of electricity demand during the normal operation period 
From Figure 3, it was identified that there was a normal operation period at the WeTu $\mathrm{Hub}$ from $27^{\text {th }}$ August to $7^{\text {th }}$ October 2020. The carpet plot in Figure 4 shows the extracted normal operation period.

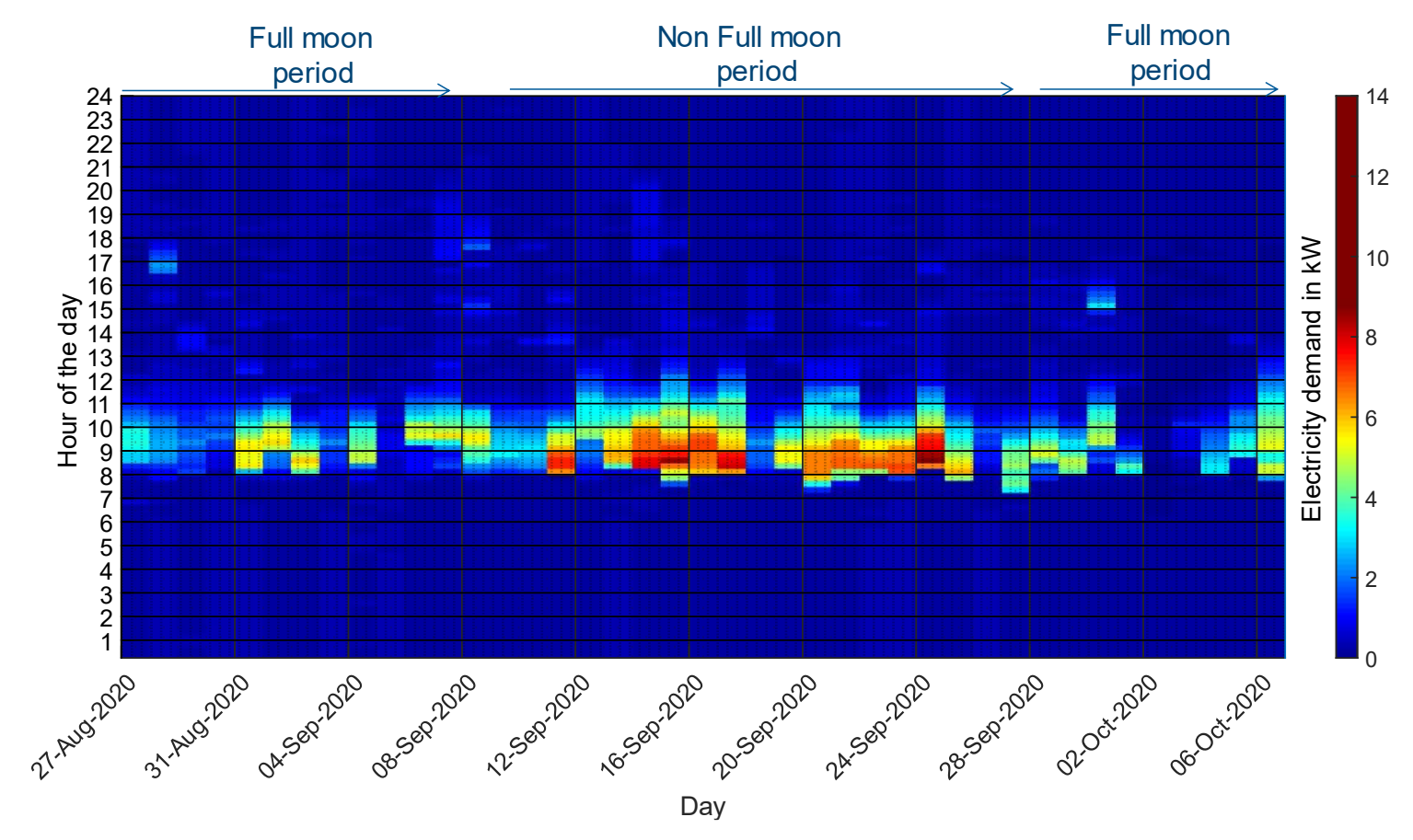

Figure 4. Carpet plot of measured electricity consumption data from Mbita WeTu Hub during the normal operation period.

The 2020 gregorian calendar was used to identify weekends and weekdays, while the 2020 lunar calendar [38] was used to identify moon phases. From Figure 4, it can be seen that there is less electricity demand from $27^{\text {th }}$ August to $7^{\text {th }}$ September, and from $27^{\text {th }}$ September to $6^{\text {th }}$ October. This was as a result of full moon phases. Moon phases are days within the moon cycle in a month. These days consist of full moon days and non-full moon days. There are approximately 10 full moon days in every month of the year. During full moon phases, there is naturally a low fishing catch on Lake Victoria because there is too much light for the fish to come to the top, and otherwise happens during non-full moon phases. In the case of the latter non-full moon phase, the fishermen utilise floatable electric lamps on the lake to attract small insects, yielding the fish to come to the water surface where they are caught by the fishermen. In the case of full moon conditions, however, the bright moonlight distracts the insects from the floatable lamps, and, as a consequence, there is less fishing catch.

Therefore, a smaller number of fishing lanterns are charged at the Mbita WeTu Hub during full moon phases. Figure 5 shows the daily electricity demand in correlation to moon phases for the normal operation period. 


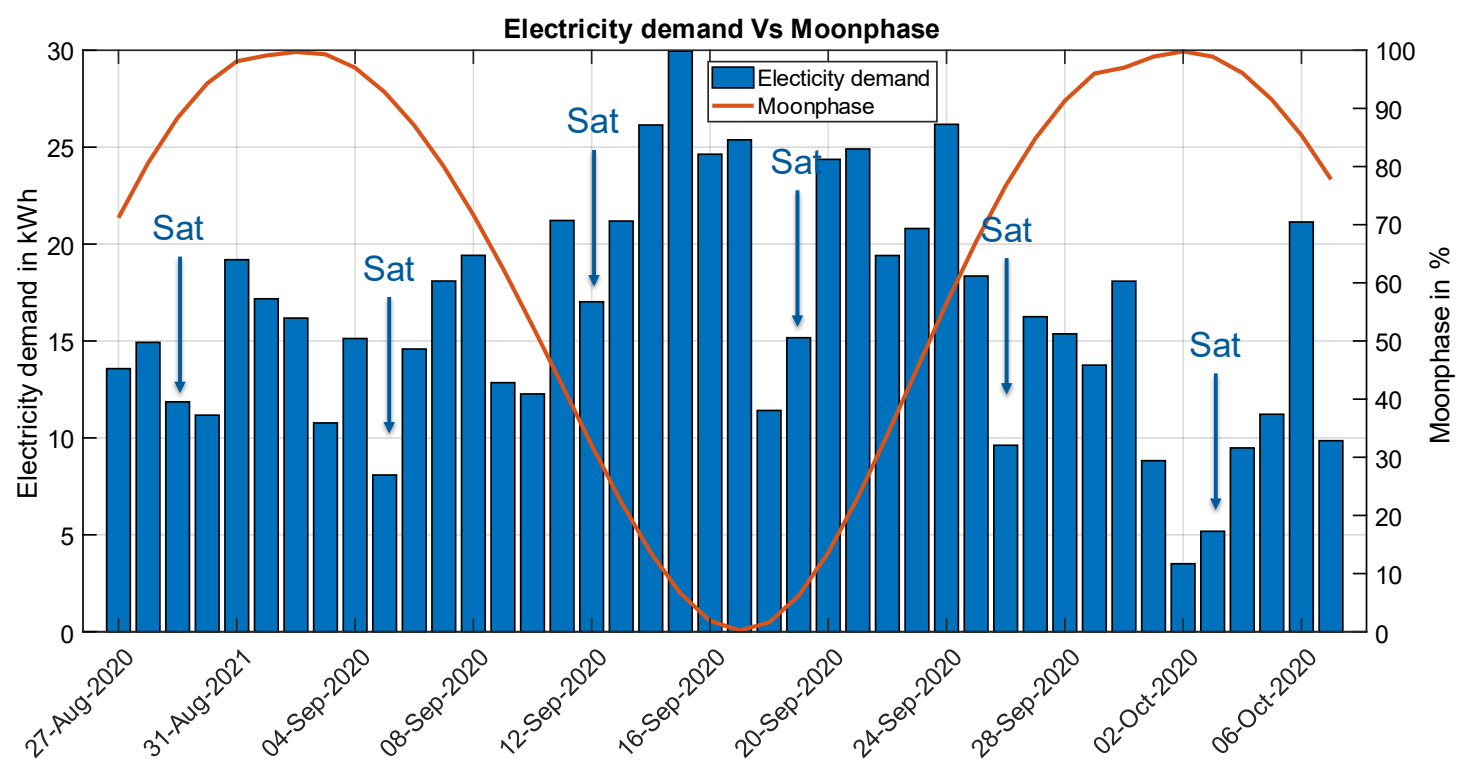

Day

Figure 5. Daily electricity demand in correlation to moon phases for the normal operation period.

6. 2 Extraction of electricity demand profile for weekdays, weekends during moon phases

Weekdays, weekends during moon phases from 27th August $2020-6^{\text {th }}$ October 2020 were extracted from the data of Figure 5. A MATLAB script was written to extract the average hourly electricity demand profile from the measurement data shown in Figure 5 for weekdays, weekends during a full moon phase, and non - full moon phases (see Figure 6, Figure 7, and Figure 8).

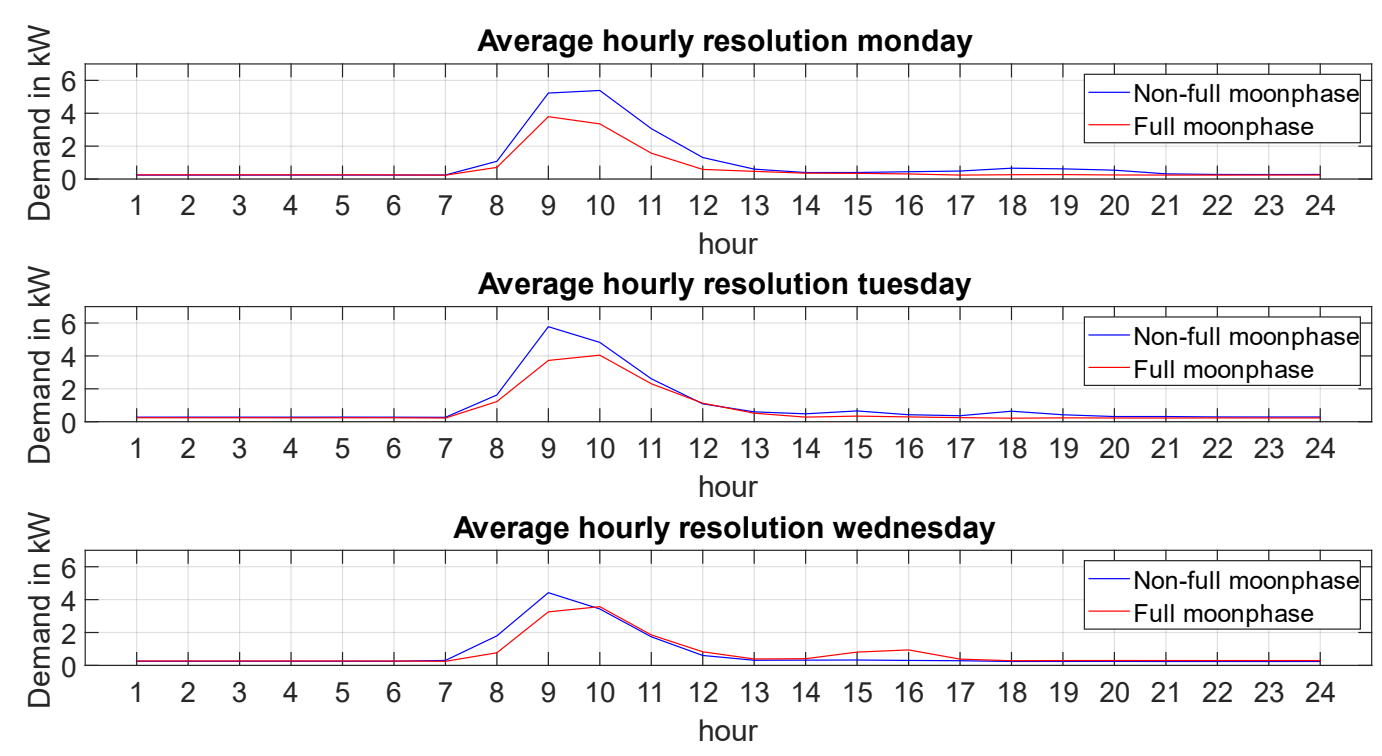

Figure 6. Average hourly electricity demand profile from the measurement during moon phases. 

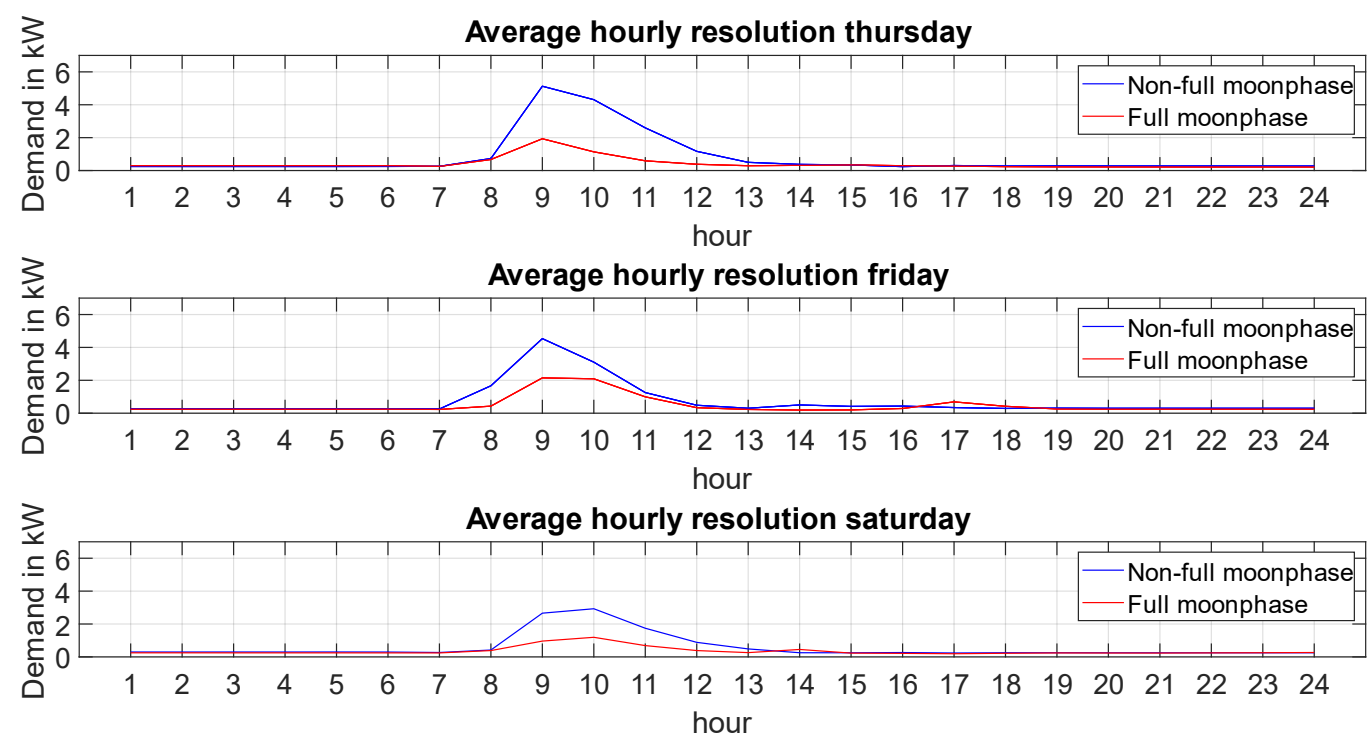

Figure 7. Average hourly electricity demand profile from the measurement during moon phases.

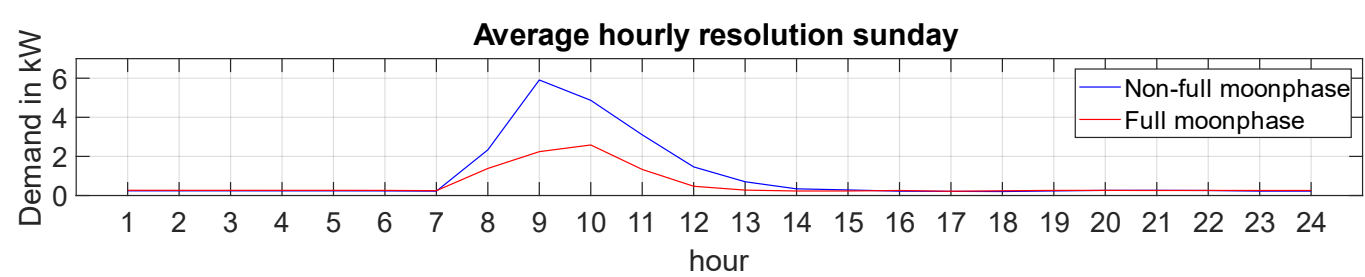

Figure 8. Average hourly electricity demand profile from the measurement during moon phases.

\subsection{Annual load profile generation}

An hourly resolution annual load profile for the Mbita WeTu Hub was generated using the extracted profiles in Figure 6, Figure 7, and Figure 8. A MATLAB script was also used to generate the year 2021 annual electricity load profile of $6,278 \mathrm{kWh} /$ year (see Figure 9). Weekdays and weekends used the gregorian calendar of 2021 and for moon phase days, the lunar calendar of 2021 was used.

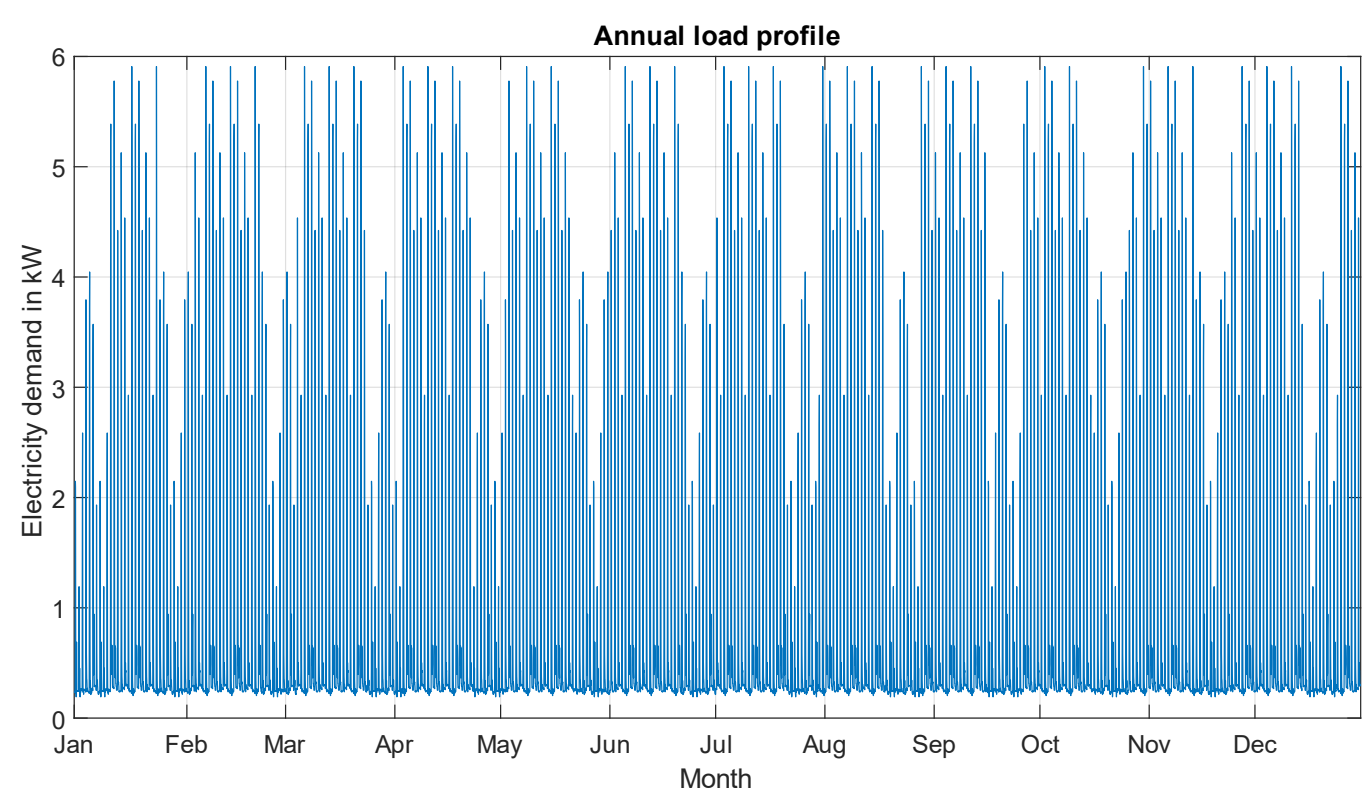

Figure 9. Annual hourly electricity demand profile from the measurement during moon phases. 


\subsection{Simulation Model of the Mbita WeTu Hub}

The annual load profile generated in the previous chapter was used as input to a simulation model. Similarly, corresponding historical annual weather data [39] of Mbita town was converted into a mathematical model and fed as input to the simulation model. The mathematical model is then able to calculate annual PV electricity production or annual electricity demand with sufficient accuracy in hourly resolution for one year. Consequently, for example, hours with a high electricity deficit can be identified.

\subsubsection{Method}

A suitable simulation model was developed using the CARNOT toolbox in MATLAB / SIMULINK simulation environment [40, 41]. The relevant components such as PV modules, inverters, battery storage, battery inverters (see Figure 10) have been parameterised according to the available datasheets. A PV field with a total of $30 \mathrm{kWp}$ is converted into alternating current using a 30-kVA inverter (see Figure 10, left) to either cover the electrical load profile demands of the Mbita WeTu Hub (see Figure 10, above) or charge a central backup battery storage system of $104 \mathrm{kWh}$ (see Figure 10, right).

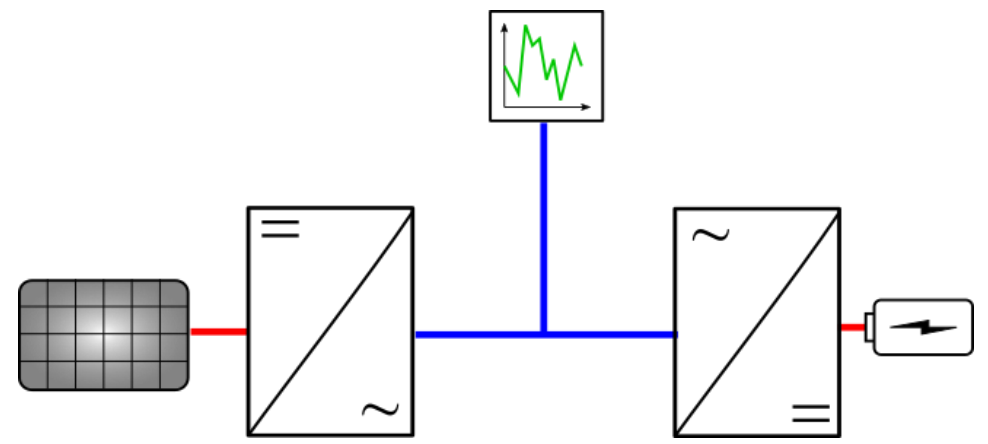

Figure 10. The layout of the developed PV system simulation model.

The Conventional and Renewable Energy Optimization Toolbox (CARNOT) is used as a tool for modelling the Mbita WeTu Hub PV system size to cover the electric demand requirements. Similarly, modelling of a yield simulation requires a time-series of input weather data like solar irradiation, ambient temperature, load profile, and other technical parameters of the planned PV systems [42].

The CARNOT tool allows a MATLAB / Simulink time-series assessment of the system's electricity production, consumption, battery SoC, inverter efficiency, and electricity deficit.

The CARNOT PV model uses a CARNOT block set in a MATLAB / Simulink environment that consists of weather data, PV module orientation, PV modules. The CARNOT tool uses a block set called 'PV module' to simulates and calculates the output power $(\mathrm{P})$ of the PV module in watt (W) based on the module characteristic parameter using the equation below:

$\mathrm{P}=\frac{\mathrm{S}_{\mathrm{R}}}{\mathrm{I}_{\mathrm{R}}} \times \mathrm{IAM} \times \mathrm{P}_{\max } \times\left(1-\left(\mathrm{T}_{\mathrm{a}}+\mathrm{T}_{\mathrm{d}} \times \frac{\mathrm{S}_{\mathrm{p}}}{\mathrm{I}_{\mathrm{R}}}\right)-\mathrm{M}_{\mathrm{T}}\right)$

where:

$\begin{array}{cl}\mathrm{P} & =\text { output power of the PV module in } \mathrm{W} \\ = & \text { solar radiation } \\ = & \text { incident radiation at } \mathrm{STC}: 1000 \mathrm{~W} / \mathrm{m}^{2} \\ = & \text { incidence angle modifier: } 1 \text { for vertical direct } \\ & \text { solar radiation. It follows the reflection law } \\ \mathrm{I}_{\mathrm{R}} & \text { of Fresnel. } \\ = & \text { peak power }\left(\mathrm{W}_{\mathrm{P}}\right) \text { at } \mathrm{STC} \text { in } \mathrm{W} \\ \mathrm{IAM} & \text { ambient temperature } \\ = & \text { temperature difference to ambient at full so- } \\ \mathrm{P}_{\max } & \text { lar radiation }\left(1000 \mathrm{~W} / \mathrm{m}^{2}\right): 40 \mathrm{~K} \\ \mathrm{~T}_{\mathrm{a}} & \end{array}$


$=$ solar power

$=$ module temperature at STC: $25^{\circ} \mathrm{C}$

6.4.2 Simulation results

Figure 11 shows the total annual hourly PV electricity production of $37,785 \mathrm{kWh}$, the electricity demand of $6,278 \mathrm{kWh}$, and the electricity surplus of $30,493 \mathrm{kWh}$. There was a 0 kWh electricity deficit obtained because the PV system can cover the whole annual electricity demand. It can also be seen in Figure 11 that the battery SoC wasn't below $80 \%$ because of low electricity demand. Therefore, the number of e-bike batteries to be charged daily at the WeTu Hub will be assumed in line with the obtained electricity surplus.

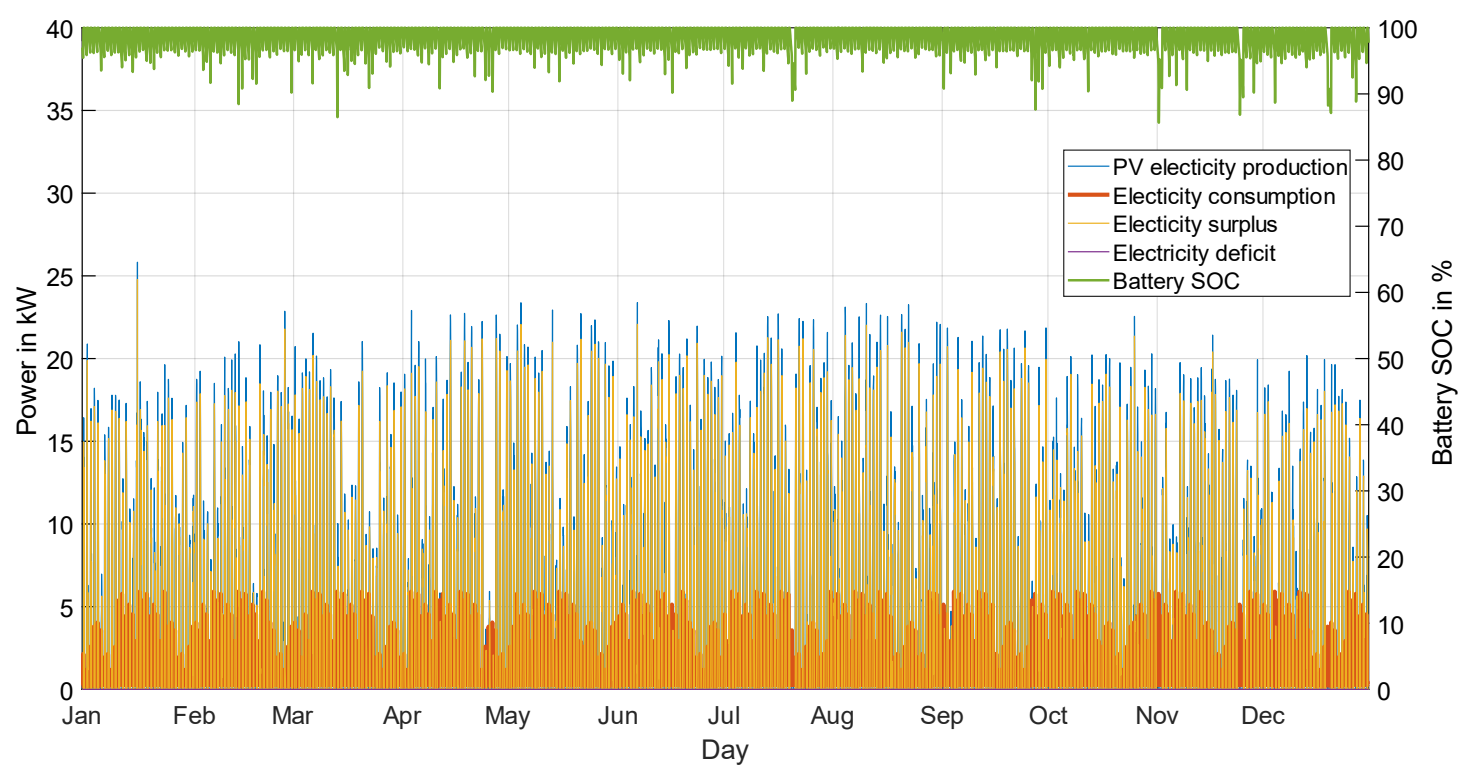

Figure 11. Annual hourly PV electricity production, demand, surplus in kW.

\section{Field measurement investigation on e-bikes}

Various driving tests have been carried out on the e-bikes by MOI university and WeTu engineers at Mbita to measure the distance-related energy consumption (kWh / $100 \mathrm{~km}$ ) of the bikes. During the field measurement, trip distance, terrain, speed, and payload weight of the bikes were taken into consideration.

The test's outcome, which aims to quantify battery energy usage in $\mathrm{kWh}$ per $100 \mathrm{~km}$, will aid in determining how many batteries swaps a rider may require per daily trip distance. As a result, the data can be used to optimise the integration of e-bikes into the WeTu Hub.

7.1. Measurement investigation on OpiBus bike

The OpiBus bike batteries' energy recording and assessment results were determined. The distance traveled, the payload of the bike (driver + passenger), and the energy requirement $(\mathrm{kWh} / 100 \mathrm{~km}$ ) were among the other data determined (see Figure 12). Depending on the road surface, 7 separate tests were conducted on tarmac-surfaced routes and 6 different tests on non-tarmac-surfaced routes (i.e., gravel or soil roads were evaluated). Figure 12 depicts a graphical representation of the OpiBus bike's battery energy requirement as a function of the road surface. It can be seen that driving on non-tarmac terrain consumes more energy than driving on tarmac. From the evaluation process, it can be seen that battery test number 4 has a lower energy consumption of $6 \mathrm{kWh} / 100 \mathrm{~km}$ at an average payload weight of $160 \mathrm{~kg}$ and an average speed of $45 \mathrm{~km} / \mathrm{hr}$ than in contrast to battery test number 3 where higher energy consumption of $6.3 \mathrm{kWh} / 100 \mathrm{~km}$ at a payload $80 \mathrm{~kg}$ at speed of $45 \mathrm{~km} / \mathrm{hr}$. This may be attributed to the landscape (i.e., gradient angle) of the road surface which was not recorded during the measurement investigation. The average battery electricity demand on tarmac terrain was $5.7 \mathrm{kWh} / 100 \mathrm{~km}$ at an average payload of $145 \mathrm{~kg}$ at $50.7 \mathrm{~km} / \mathrm{hr}$. The average battery electricity demand on non 
- tarmac terrain was $7.3 \mathrm{kWh} / 100 \mathrm{~km}$ at an average payload of $136 \mathrm{~kg}$ at $45.8 \mathrm{~km} / \mathrm{hr}$. The total test distance-related average electricity consumption on both terrains was $6.4 \mathrm{kWh} /$ $100 \mathrm{~km}$ at an average payload of $141 \mathrm{~kg}$ at $48.5 \mathrm{~km} / \mathrm{hr}$. Therefore, it can be concluded that an OpiBus bike with $2.16 \mathrm{kWh}$ battery capacity running at an average payload of $141 \mathrm{~kg}$ and, at an average speed of $48 \mathrm{~km} / \mathrm{hr}$ would require at least 2 batteries swap to cover a trip of $100 \mathrm{~km} /$ day. This is comparatively in line with the report of [34] that an electric motorcycle has a real-world energy consumption varying from $0.71 \mathrm{kWh} / 100 \mathrm{~km}$ to 9.3 $\mathrm{kWh} / 100 \mathrm{~km}$.

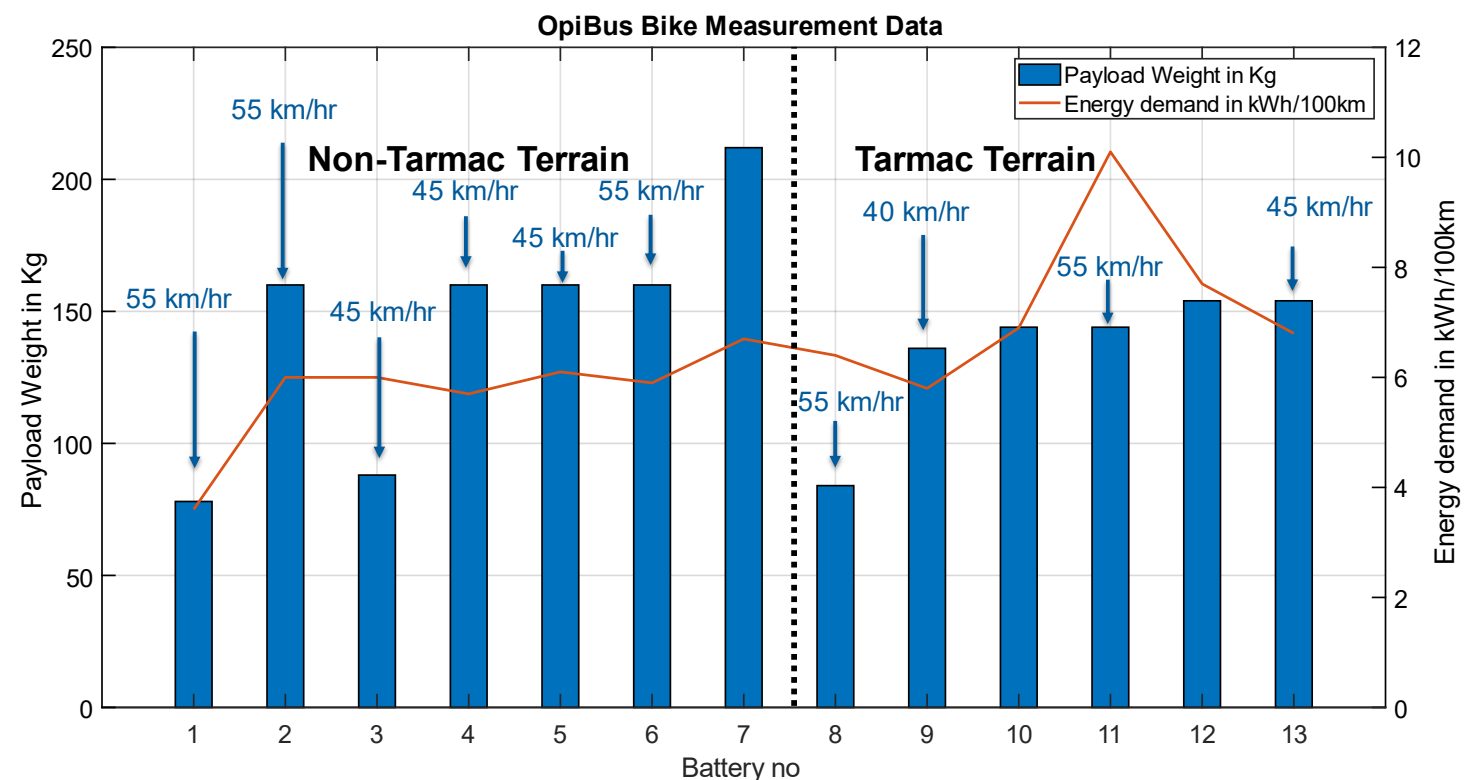

Figure 12. Battery electricity demand depending on the road surface (OpiBus).

\subsection{Measurement investigation on BodaWerk bike}

An investigation on the BodaWerk bike was done in the same manner as the investigations on the OpiBus batteries. Among other metrics, the distance traveled, the payload of the bike, and the energy usage $(\mathrm{kWh} / 100 \mathrm{~km})$ were determined. Five distinct tests were carried out on tarmac-surfaced routes. Figure 13 depicts a graphical representation of the battery energy requirement for the BodaWerk bike on a tarmac road surface. According to Figure 13, the average battery energy consumption on the tarmac terrain was $3.9 \mathrm{kWh}$ / $100 \mathrm{~km}$ at an average payload weight of $74 \mathrm{~kg}$ and an average speed of $39 \mathrm{~km} / \mathrm{hr}$ during the assessment phase. As a result, it is possible to deduce that a BodaWerk bike with $2.2 \mathrm{kWh}$ battery capacity running at an average payload of $74 \mathrm{~kg}$ and, at an average speed of $39 \mathrm{~km} / \mathrm{hr}$ would require at least 1 battery swap to cover a trip of $100 \mathrm{~km}$. This is comparatively in line with the report of [43] that an electric motorcycle has a real-world energy consumption varying from $0.71 \mathrm{kWh} / 100 \mathrm{~km}$ to $9.3 \mathrm{kWh} / 100 \mathrm{~km}$. This has further confirmed the report of [44] that a BodaWerk bike with $2.2 \mathrm{kWh}$ battery capacity operating at an average payload of over $70 \mathrm{~kg}$ would require at least 1 battery swap for $100 \mathrm{~km}$ range. 


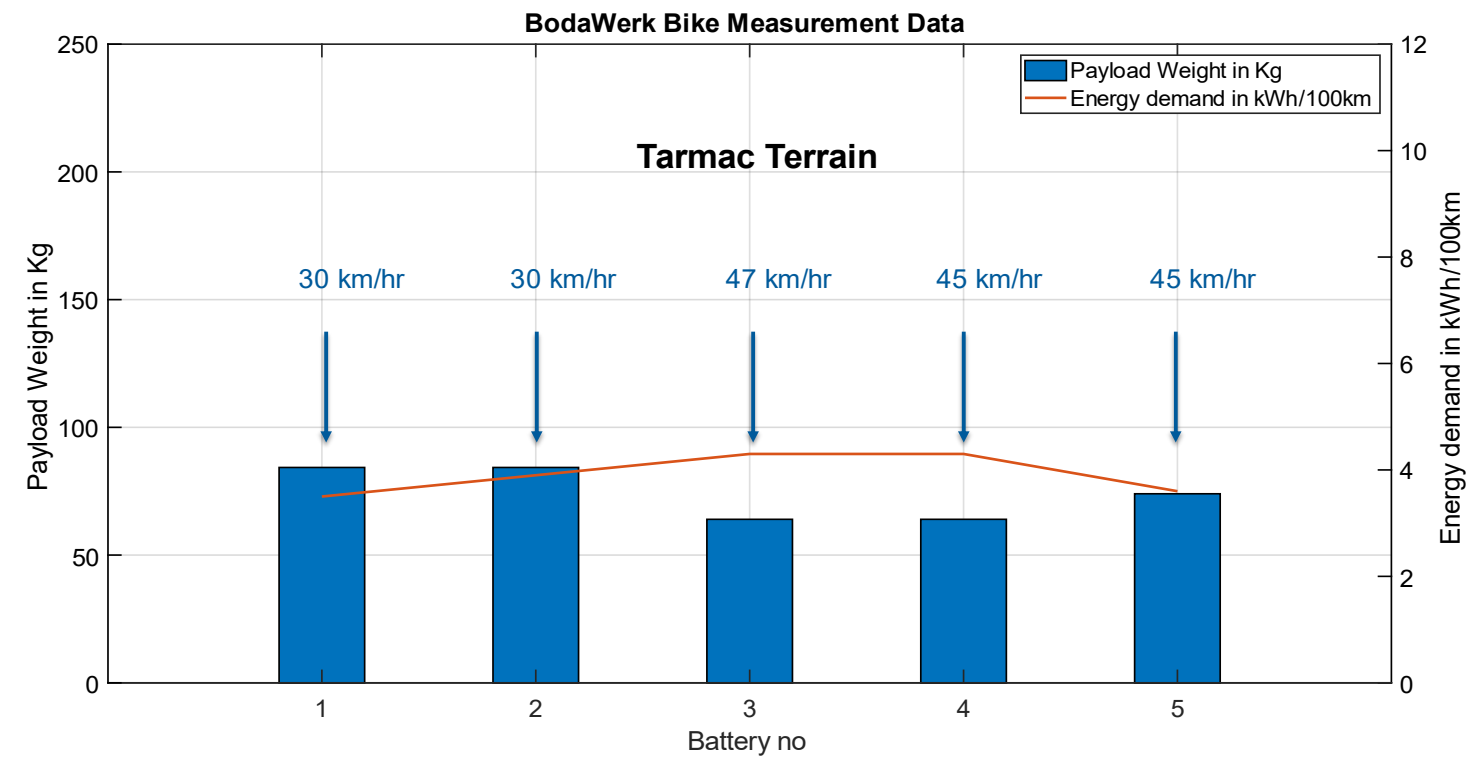

Figure 13. Distance-related battery electricity demand depending on the road surface (Bodawerk).

\subsection{Measurement investigation on Cargo bike}

Furthermore, testing was performed on the business Anywhere Berlin's electrically powered cargo bicycles. Figure 14 depicts the evaluation of the particular, distance-related energy consumption in $\mathrm{kWh} / 100 \mathrm{~km}$. Four distinct tests were conducted on nontarmac roads, and one test was conducted on mixed terrain (tarmac and non-tarmac). According to Figure 14, the average battery energy requirement over non-tarmac terrain was $3.3 \mathrm{kWh} / 100 \mathrm{~km}$ at an average payload of $86 \mathrm{~kg}$ and an average speed of $22.7 \mathrm{~km} / \mathrm{hr}$ during the assessment procedure. The average battery energy requirement over mixed terrain was $10.2 \mathrm{kWh} / 100 \mathrm{~km}$ with a payload weight of $210 \mathrm{~kg}$ and a speed of $24 \mathrm{~km} / \mathrm{hr}$. On both terrains, the total test distance-related average power consumption was $4.2 \mathrm{kWh}$ / $100 \mathrm{~km}$ with a payload weight of $102 \mathrm{~kg}$ at $22.9 \mathrm{~km} / \mathrm{hr}$. As a result, a cargo bike with a $1.1 \mathrm{kWh}$ battery capacity and an average payload weight of $102 \mathrm{~kg}$, and an average speed of $22.9 \mathrm{~km} / \mathrm{hr}$ would require at least three battery swaps to cover a $100 \mathrm{~km}$ journey. This is in line with the report of [44] that a 4-kWh battery capacity would be required for an 80 $\mathrm{km}$ range on Anywhere Berlin cargo bike.

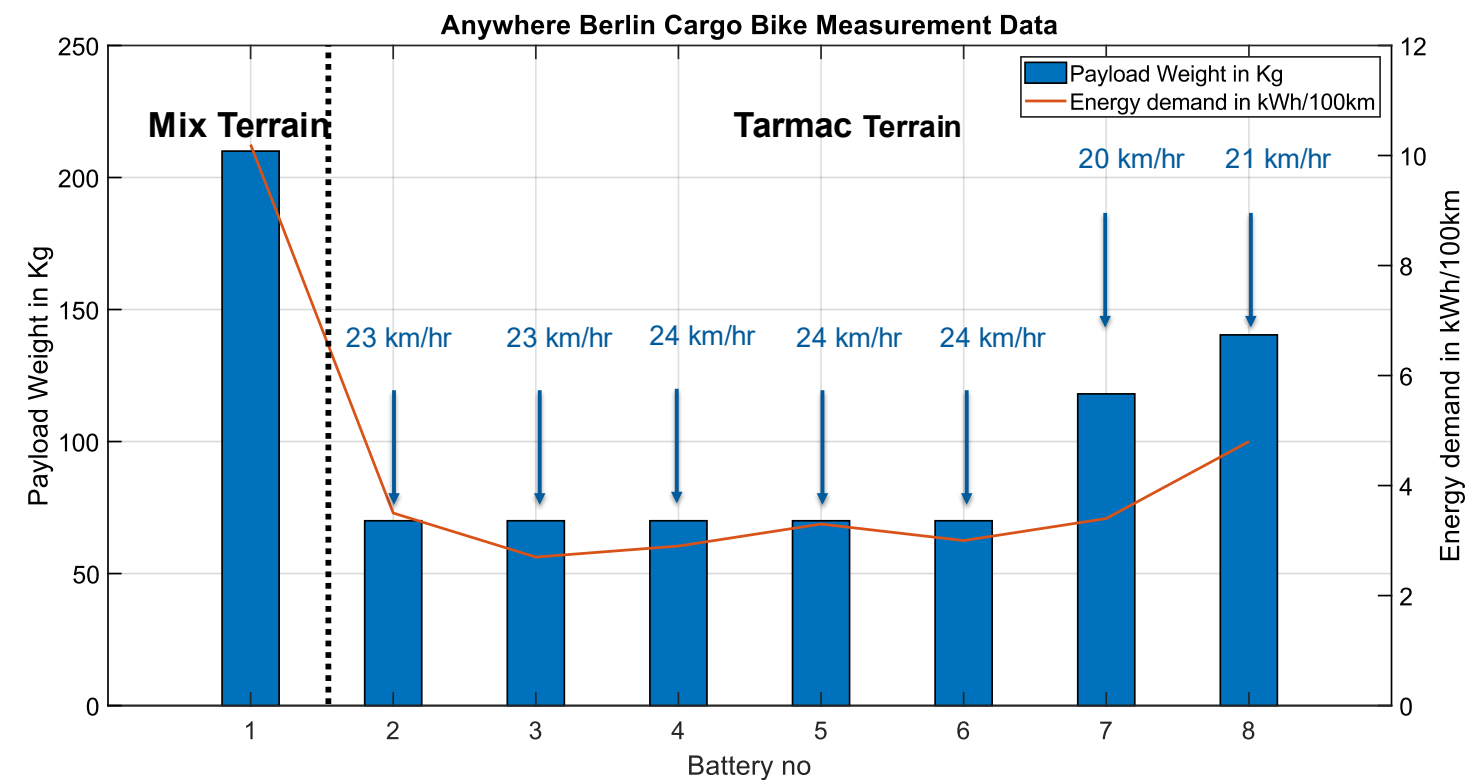


Figure 14. Distance-related battery electricity demand depending on the road surface (Anywhere Berlin cargo bikes).

The summary of the future consumer (i.e., e-bikes) measurement results is shown in Table 4. It can be seen that the OpiBus bike has an average energy usage per recharge of $2.16 \mathrm{kWh}$ with an average energy requirement of $6.3 \mathrm{kWh} / 100 \mathrm{~km}$ at $129 \mathrm{~kg}$ average payload (rider + passenger). The BodaWerk bike has an average energy usage per recharge of $2.2 \mathrm{kWh}$ with an average energy requirement of $3.9 \mathrm{kWh} / 100 \mathrm{~km}$ at a $74.12 \mathrm{~kg}$ average payload. The cargo bike has an average energy usage per recharge of $1.05 \mathrm{kWh}$ with an average energy requirement of $4.23 \mathrm{kWh} / 100 \mathrm{~km}$ at a $102.31 \mathrm{~kg}$ average payload. It is clear from Table 4 that the energy demand in $\mathrm{kWh}$ for the different bikes differs from each other. The BodaWerk bike has the lowest energy demand of $3.93 \mathrm{kWh} / 100 \mathrm{~km}$ while the OpiBus has the highest energy demand of $6.3 \mathrm{kWh} / 100 \mathrm{~km}$. This can partly be attributed to the different payload weights on the bikes. However, further effects that were not considered during the measurement phase have to be further investigated such as the gradient of the road surface. The energy demands recorded during the measurement are still in line with what other studies have indicated that the certified and real-world energy consumption for e-bikes vary between 0.17 and $9.3 \mathrm{kWh} / 100 \mathrm{~km}$ [43].

Table 4. Summary of electric bikes measurement results.

\begin{tabular}{|c|c|c|c|c|c|c|c|}
\hline $\begin{array}{l}\text { Type } \\
\text { of } \\
\text { load }\end{array}$ & $\begin{array}{c}\text { Battery } \\
\text { Size in } \\
\text { kWh }\end{array}$ & $\begin{array}{c}\text { Distance } \\
\text { covered in } \\
\text { km }\end{array}$ & $\begin{array}{c}\text { Weight } \\
\text { in } \\
\text { kg }\end{array}$ & $\begin{array}{c}\text { Speed } \\
\text { In } \\
\text { km/h }\end{array}$ & $\begin{array}{c}\text { Charge } \\
\text { time } \\
\text { in } h\end{array}$ & $\begin{array}{c}\text { Charge } \\
\text { rate } \\
\text { in } W\end{array}$ & $\begin{array}{c}\text { Energy } \\
\text { demand in } \\
\text { kWh/100km }\end{array}$ \\
\hline OpiBus & 2.16 & 36.89 & 129.84 & 47.80 & 2.7 & 800.00 & 6.40 \\
\hline BodaWerk & 2.20 & 48.12 & 74.12 & 39.40 & 2.4 & 900.00 & 3.60 \\
\hline E-Cargo & 1.05 & 29.03 & 102.31 & 22.88 & 5.0 & 200.00 & 4.23 \\
\hline
\end{tabular}

The measurement analysis determined the quantity of daily power and energy required to charge the e-bike batteries. The results of the measurement analysis aided in the development of hourly, daily, and annual load profiles (see next chapter) for each bike, considering energy consumption, battery capacity, charging power and charging time.

\section{Integration of e-bikes and additional fishing lanterns into WeTu $\mathrm{Hub}$}

A scenario was used to describe the prospective integration of the e-bikes into the WeTu Hub considering the surplus obtained in Figure 11. The scenario considered / assumed different numbers of e-bike batteries and additional lanterns depending on the type of day (see Table 5).

Table 5. System Design Scenario for load profile generation.

\begin{tabular}{cccccc}
\hline $\begin{array}{c}\text { Type } \\
\text { of } \\
\text { day }\end{array}$ & $\begin{array}{c}\text { Bodawerk } \\
\text { battery } \\
\text { target }\end{array}$ & $\begin{array}{c}\text { Cargo } \\
\text { battery } \\
\text { target }\end{array}$ & $\begin{array}{c}\text { OpiBus } \\
\text { battery } \\
\text { target }\end{array}$ & $\begin{array}{c}\text { Fishing } \\
\text { lantern } \\
\text { target }\end{array}$ & $\begin{array}{c}\text { Total electricity de- } \\
\text { mand in } \\
\text { kWh / day }\end{array}$ \\
\hline Full moon & 9 & 6 & 9 & 100 & 51.9 \\
Non-full moon & 9 & 6 & 9 & 200 & 60.6 \\
\hline
\end{tabular}

Realistic daily runtimes for the various major electric loads shown in Table 5 were estimated, generated based on the surplus in Figure 11, and integrated into the existing load profile in Figure 9. The annual electricity profiles from the daily profiles were generated using MATLAB. The annual electricity demand of 27,267 kWh has been generated with the specific peak electricity demand of $14.8 \mathrm{kWh}$ (see Figure 15) 


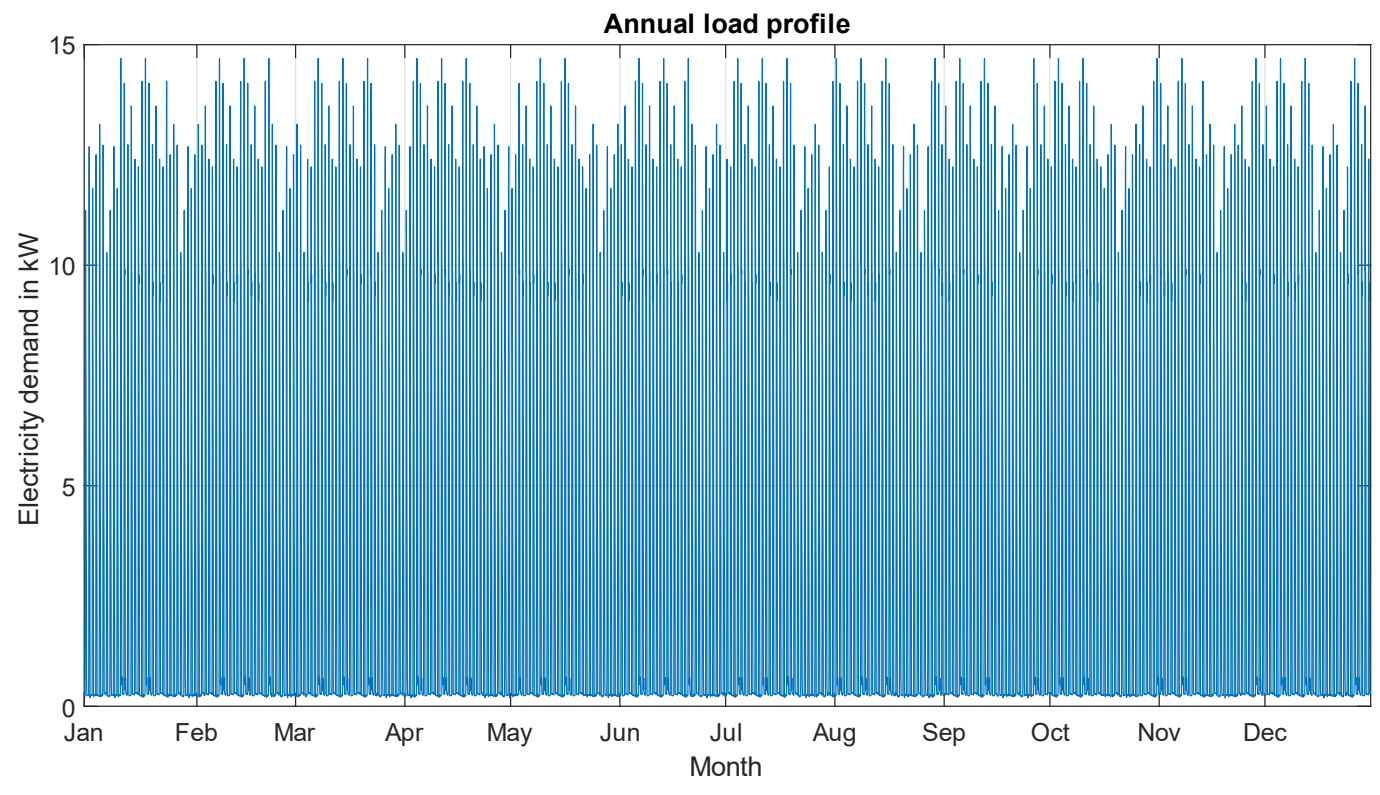

Figure 15. WeTu Hub annual hourly electricity demand profile including e-bikes.

\subsection{Result and Discussion}

Figure 16 shows the annual monthly- hourly PV electricity production, electricity demand, and electricity deficit. It can be seen that June to August has the lowest electricity deficit. November has the highest electricity deficit followed by May, then April due to weather conditions. An annual PV electricity production of $37,785 \mathrm{kWh}$, the electricity demand of $27,267 \mathrm{kWh}$, and electricity deficit of $376 \mathrm{kWh}$ were respectively obtained. Figure 17 shows the week in April with the lowest PV production, thereby yielding the highest energy deficit of $70.6 \mathrm{kWh}$ across the month.

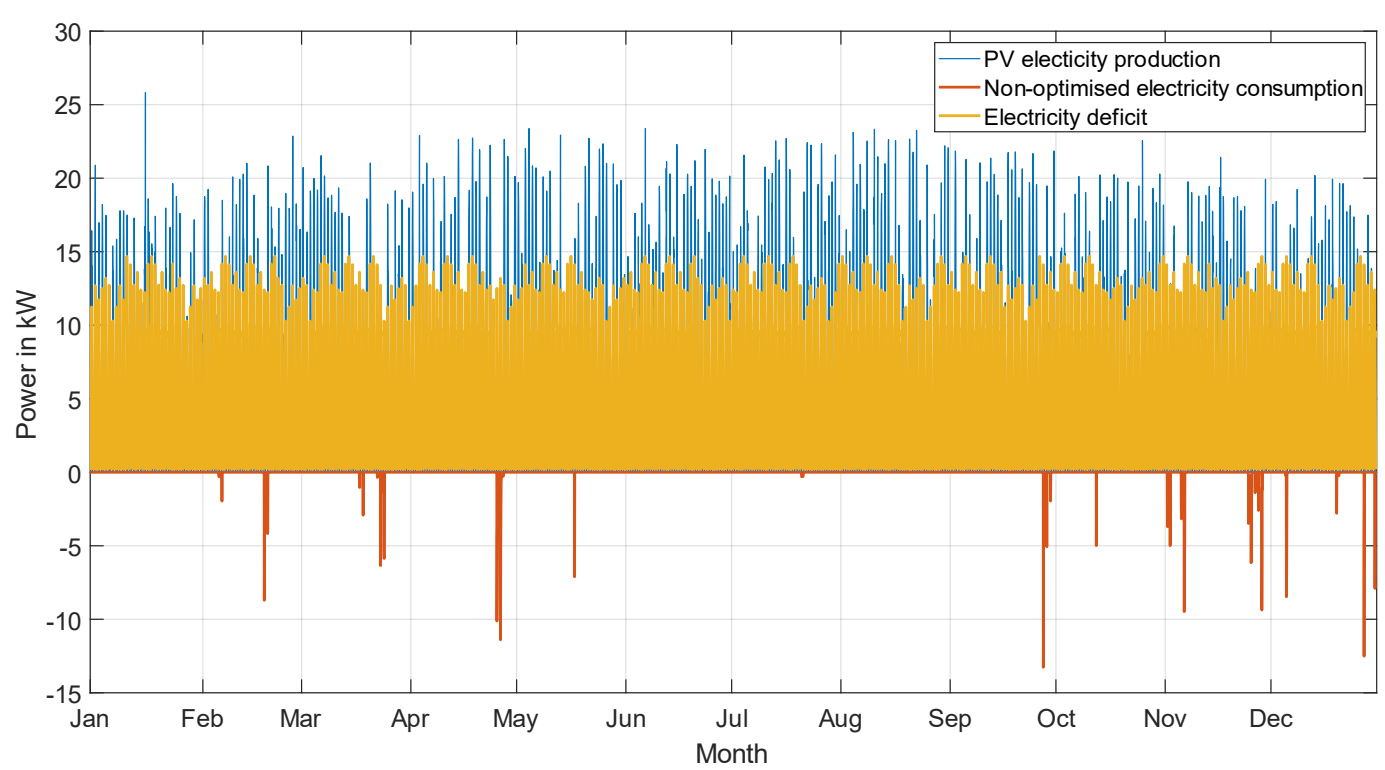

Figure 16. Annual hourly PV electricity production, demand, and deficit in $\mathrm{kW}$ 


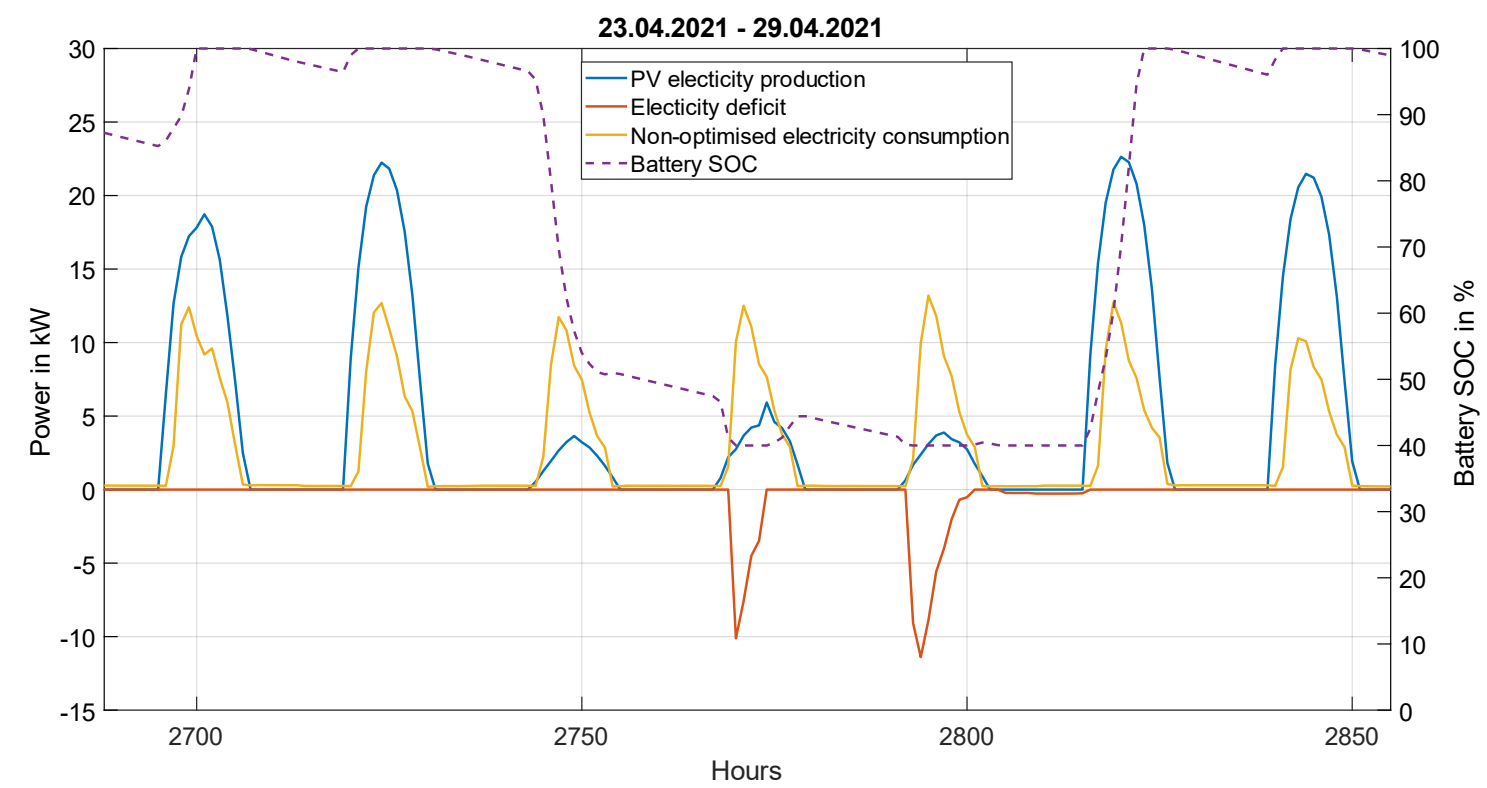

Figure 17. Hourly PV electricity production, demand, and deficit in $\mathrm{kW}$ for a week in April (23.04 - 29.04).

It can be also seen from Figure 17 that an electricity deficit was obtained between hours 2768 and 2800 due to low PV electricity production and the central battery has been drained to its set minimum SoC of $40 \%$.

\section{Development of a load optimisation algorithm for Mbita WeTu $\mathrm{Hub}$}

For energy deficit reduction and optimum integration of electric mobility into the Mbita WeTu Hub PV system, a load optimisation problem was formulated which resulted in a nonlinear programming (NLP) problem. The optimisation problem helped in reducing energy deficit without necessarily increasing the PV system size, use of grid connection, or diesel generator. The optimisation model was developed to solve the NLP problem by optimising electric loads including e-bikes and fishing lanterns to properly utilise the PV generation, thereby reducing energy deficit and cost. A metrological hourly dataset for a complete year was used for the successful simulation of the PV system. A sensitivity analysis of the NLP optimisation model was carried out to evaluate the impact of the electric loads on the objective function.

\subsection{Load Optimisation using Non-Linear Programming (NLP)}

The main purpose of the load optimisation concept is to design a system that captures the maximum amount of variable PV generation, then sizes and schedules a finite number of electric loads to track available PV power. The approach is to use the MATLAB fmincon solver for $N L P$.

$N L P$ is the optimisation problem of minimising an objective function expressed by variables, subject to nonlinear equality and inequality constraints. Constraints are necessary to ensure that the load sizing is adequate, avoiding system overloads at the same time. Figure 18 shows the architecture of the NLP-based load optimisation algorithm. 


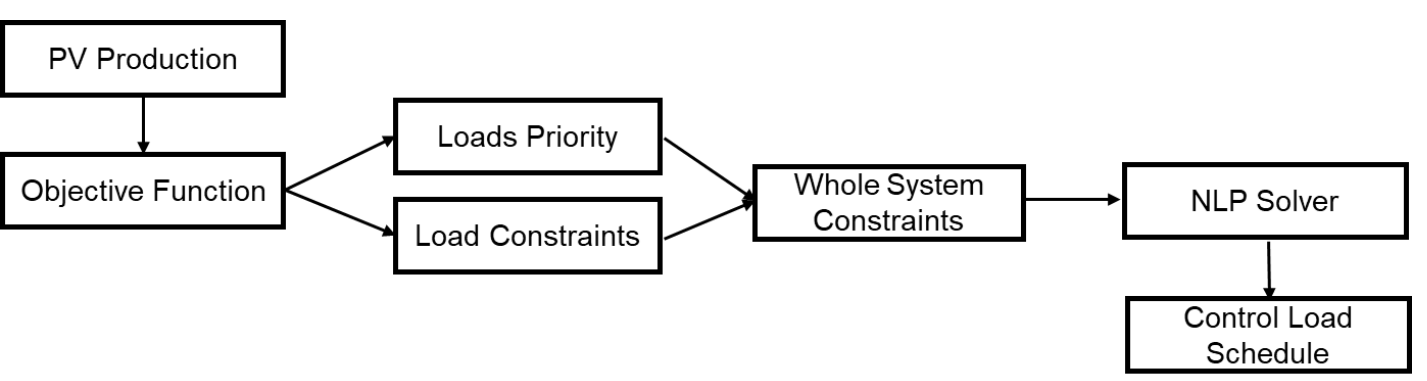

Figure 18. The architecture of the NLP-based load optimisation algorithm.

NLP optimisation problems are often solved using the branch and bound branch and cut, or branch and price algorithms. Similar to linear programming an objective function, general constraints, and variables bounds have to be solved. However, the difference is that a nonlinear program includes at least one nonlinear function, which could be the objective function or some or all of the constraints.

MATLAB nonlinear programming solver finds the minimum of a problem specified by:

$$
\text { Minimise } f^{T} x \text { subject to }\left\{\begin{array}{c}
c(x) \leq 0 \\
c e q(x)=0 \\
A \cdot x \leq b \\
\text { Aeq. } x=b e q \\
l b \leq x \leq u b
\end{array}\right.
$$

$b$ and beq, are vectors, $A$ and $A e q$ are matrices, $c(x)$ and ceq $(x)$ are functions that return vectors, and $f(x)$ is a function that returns a scalar. $f(x), c(x)$ and ceq $(x)$ can be nonlinear functions. $x, l b$, and $u b$ can be passed as vectors or matrices. Aeq. $x=b e q$ is an equality, $A . x \leq b$ and $l b \leq x \leq u b$ are inequality constraints that are considered in the optimisation problem for attaining the accurate, efficient optimal solution of the objective function.

\subsubsection{Formulation of the load optimisation problem}

The load optimisation problem is formulated by the objective function which considers the charging capacity and operational priority of each load as well as the maximum number of loads charged per hour. The fmincon solver then minimises the objective function at a given PV generation by optimally scheduling the different loads. The objective function is defined as

$$
\text { fun }=\sum_{k=1}^{n}\left(L P_{k}(t) \times A e q_{k}(t) \cdot x_{k}(t)\right)
$$

Where $L P_{k}$ is the load priority for each load at any given time $(\mathrm{t}), x_{k}$ is the hourly target of various loads that can be optimised at any given time $(\mathrm{t}), A e q_{k}$ is the charging rate of each load per hour in $\mathrm{kW}, n$ is the total number of the different loads as shown in Table 6. The final objective function for the given problem is shown in equation 5 where the first priority goes to lanterns, second, third, and fourth priority goes to e-bikes respectively.

$$
\text { fun }=\left(1 \times 37 \cdot x_{1}\right)+\left(2 \times 200 \cdot x_{2}\right)+\left(3 \times 800 \cdot x_{3}\right)+\left(4 \times 900 \cdot x_{4}\right)
$$

To maintain the balance in the system and to meet the load demand, the total demand of the loads mustn't exceed the PV-generated power (beq) at any given time (t). This is giving by

$$
\sum_{k=1}^{n}\left(A e q_{k}(t) \cdot x_{k}(t)\right)=b e q
$$


The hourly target of each load (i.e., $x_{k}, x_{k+1}$ ) that can be charged at any given time ( $\mathrm{t}$ ) should not be less than the minimum required number of each load (i.e., $l b_{k}, l b_{k+1}$ ) which is 0 and should not exceed the maximum hourly target of each load (i.e. $u b_{k}, u b_{k+1}$ ) at any given time. This is given by:

$$
l b_{k}(t) \leq x_{k}(t) \leq u b_{k}(t)
$$

$$
l b_{k+1}(t) \leq x_{k+1}(t) \leq u b_{k+1}(t)
$$

Table 6. Detailed information of the major loads at Mbita WeTu Hub.

\begin{tabular}{ccccccc}
\hline $\begin{array}{c}\text { Type } \\
\text { of } \\
\text { loads }\end{array}$ & $\begin{array}{c}\text { Daily } \\
\text { battery } \\
\text { target }\end{array}$ & $\begin{array}{c}\text { Peak sun } \\
\text { hours } \\
(\mathbf{h r})\end{array}$ & $\begin{array}{c}\text { Charing } \\
\text { time (hr) } \\
\text { per device }\end{array}$ & $\begin{array}{c}\text { Hourly } \\
\text { battery target } \\
\left(x_{k}\right)\end{array}$ & $\begin{array}{c}\text { Charging } \\
\text { rate (W) } \\
\text { per device }\end{array}$ & $\begin{array}{c}\text { Energy } \\
\text { required } \\
\text { (Wh) } \text { per } \\
\text { device }\end{array}$ \\
\hline Cargo bike & 6 & 6.5 & 7 & 5 & 200 & 1,050 \\
Lanterns & 200 & 6.5 & 2.8 & 193 & 37 & 105 \\
OpiBus bike & 9 & 6.5 & 2.7 & 4 & 800 & 2,160 \\
BodaWerk bike & 9 & 6.5 & 2.4 & 4 & 900 & 2,200 \\
\hline
\end{tabular}

Hourly target $=$ Daily battery target $\div$ (peak sun hours $\div$ charging time $)$

9.1.2 Simulation results with NLP load optimisation algorithm

Load demands for fishing lanterns and e-bike batteries were generated based on the MATLAB developed NLP load optimisation algorithm. The developed load optimisation algorithm captures the maximum amount of variable solar generation, which then sizes and schedules a finite number of loads (i.e., e-bikes, fishing lanterns) to track available intra-day solar PV power. The annual load profiles were also generated for workdays and weekends based on the moon phase.

The NLP load optimisation algorithm also can check for todays and tomorrow's PV power production and if there is a potential lack of energy in tomorrow's PV power production, part of tomorrow's loads will be shifted to today in order to avoid the risk of not meeting the daily target of tomorrow. This concept checks the surplus of today and shifts tomorrow's loads to today. Figure 21 shows the flowchart of the NLP load optimisation algorithm with the load shifting concept.

After NLP optimisation, an annual load profile of 30,767 kWh was generated which is an $11 \%$ increased over the non-optimised load profile of $27,267 \mathrm{kWh}$. This increase is enough to charge 4 additional OpiBus bike batteries daily. Figure 19 shows the hourly results of the electricity PV production, demand, and deficit after load shifting and optimisation. An annual PV electricity production and a reduced deficit of $37,785 \mathrm{kWh}$ and 1 $\mathrm{kWh}$ were respectively obtained from the simulated PV system. 


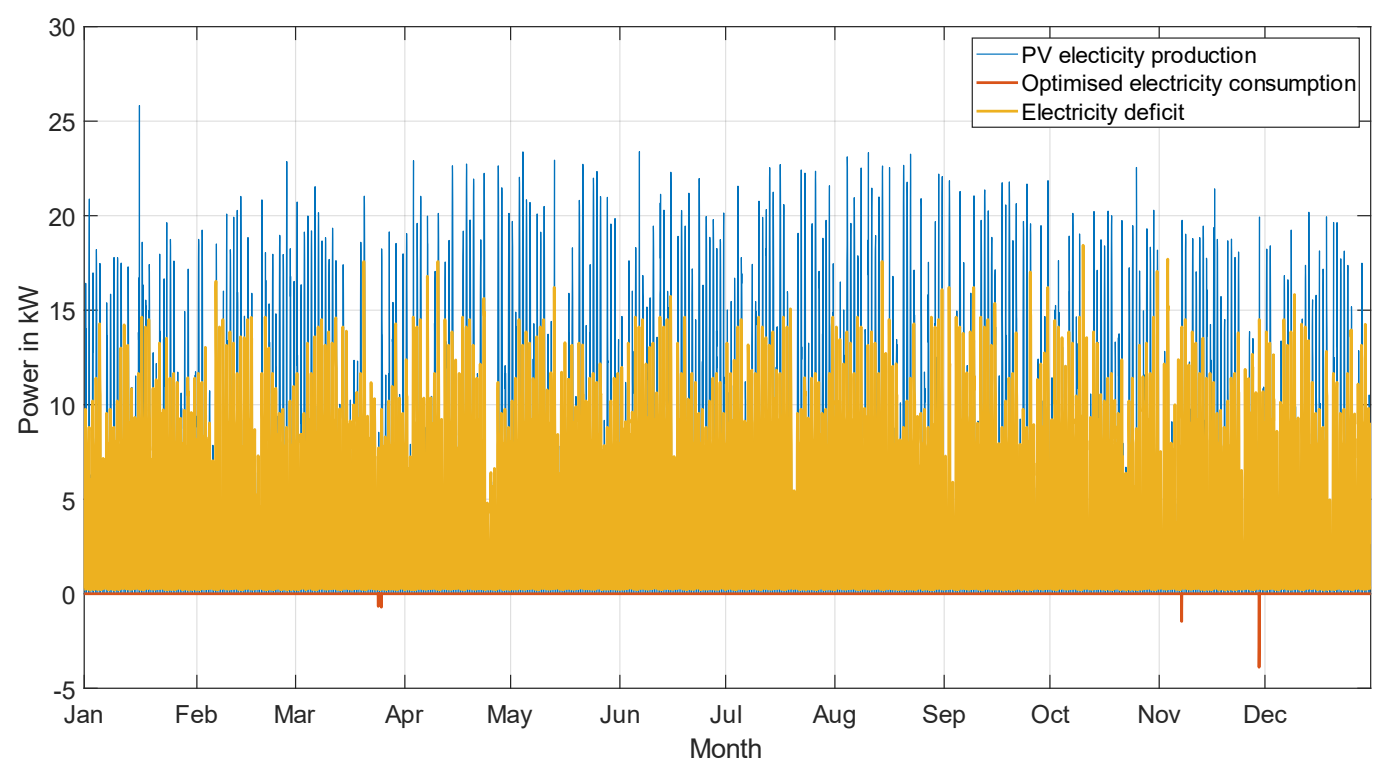

Figure 19. Hourly results after load shifting and optimisation.

Figure 20 shows the result of Figure 17 after load shifting. After optimisation, the electricity deficit was reduced by shifting and optimising the major daily loads which are shown in Figure 20. However, some loads of hours 2744 to 2756 in Figure 20 were shifted to hours between 2718 and 2730 because of the potential lack of energy in hours 2744 to 2756. The load shifting is limited to the number of available devices to be charged for hours 2744 to 2756 and the energy surplus of hours 2718 to 2730 .

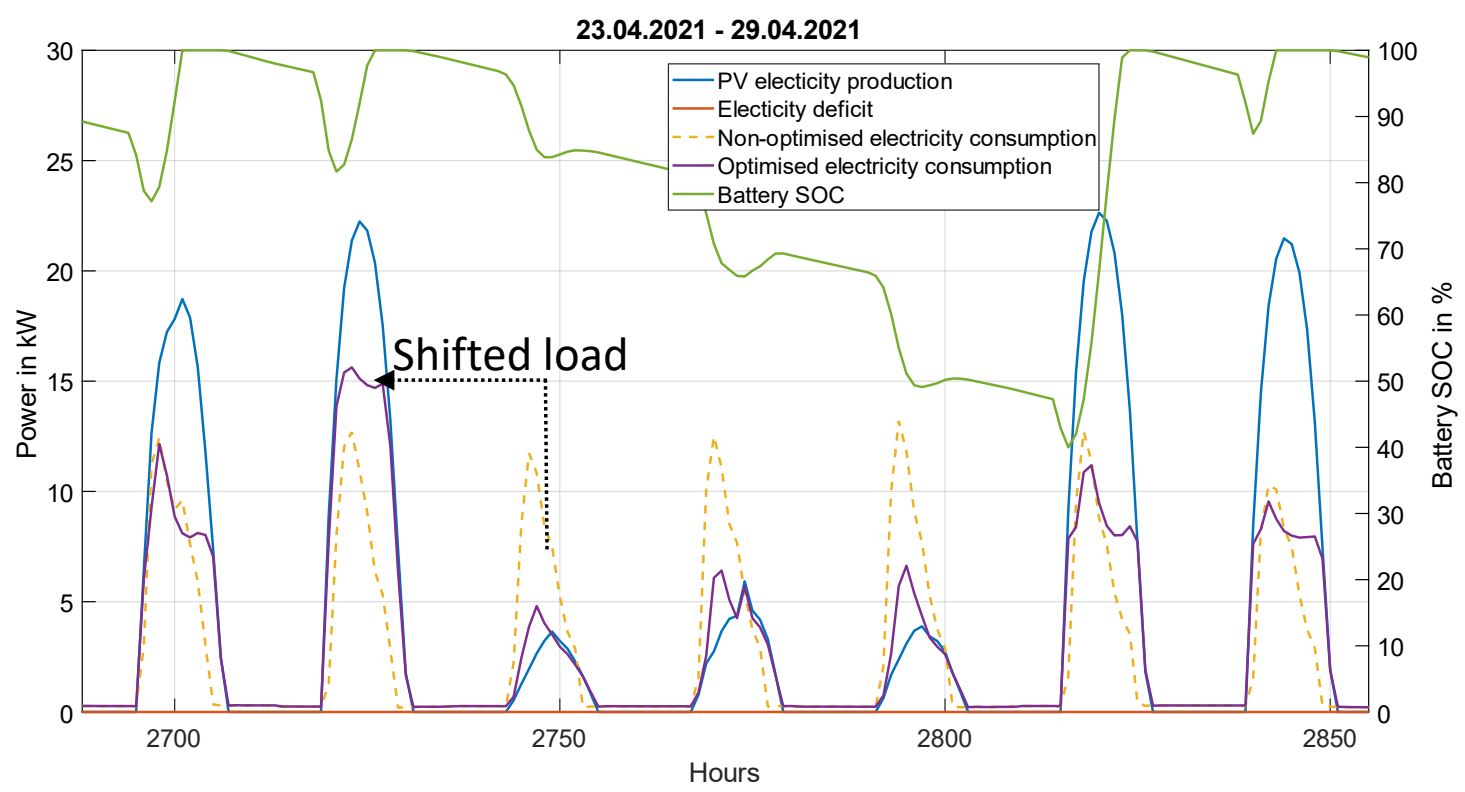

Figure 20. A week in April after load shifting and optimisation. 


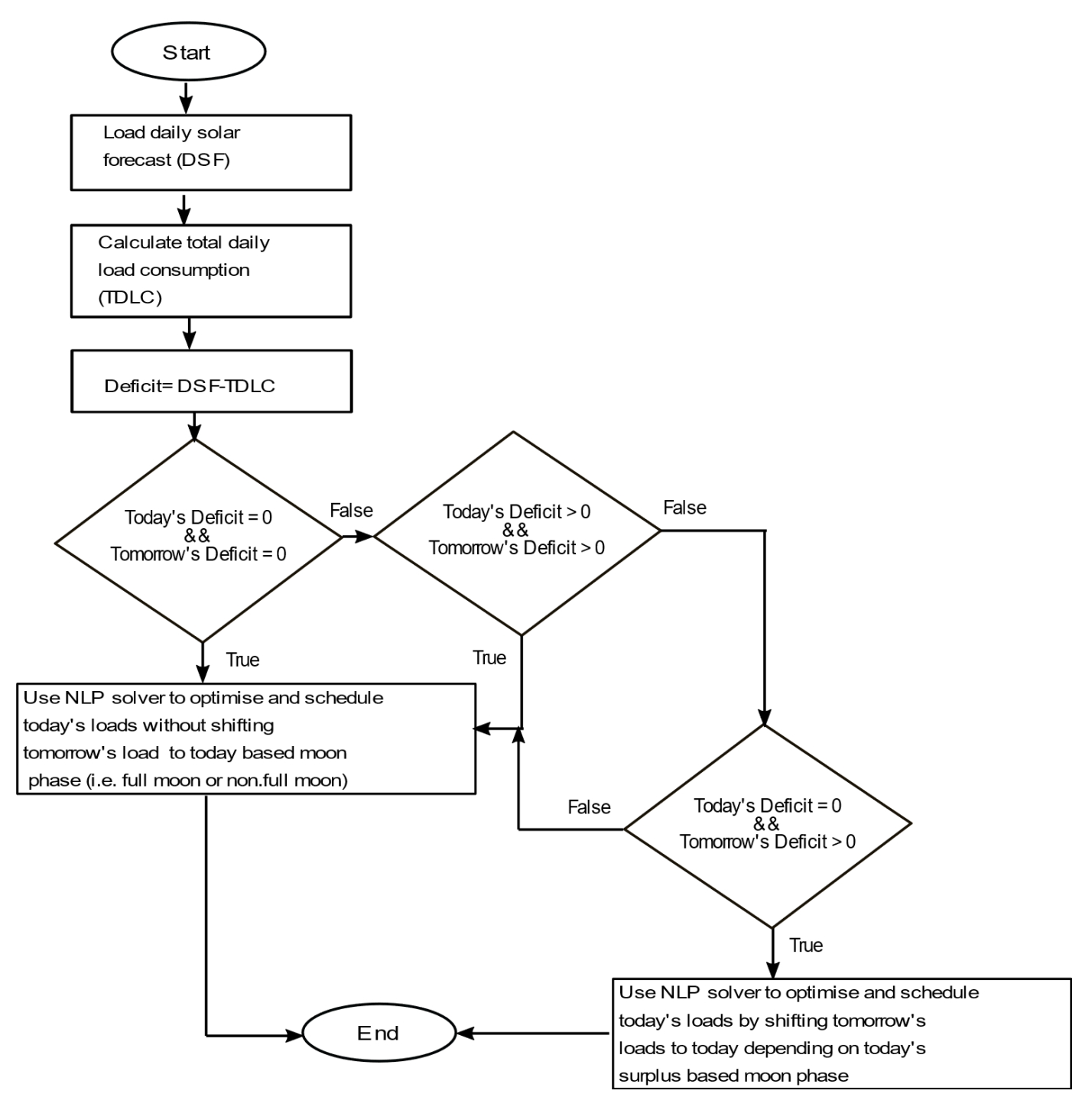

Figure 21. Flowchart of the NLP load optimisation algorithm with load shifting concept.

The development of a load optimisation scheme using MATLAB NLP algorithm for optimum integration of the e-bikes solutions into the Mbita WeTu Hub off-grid PV system helped in reducing energy deficit without necessarily increasing the PV system size, the use of grid connection or diesel generator.

The results obtained show that the system with the NLP algorithm was able to prioritise, schedule, and optimise the major loads' demand in line with intra-day PV production. The NLP algorithm was also able to shift loads of days with a potential lack of energy to the days with surplus energy based on the moon phase.

Furthermore, the NLP algorithm was able to generate more annual electricity demand of $30,767 \mathrm{kWh}$ which is $11 \%$ more than the annual electricity demand of $27,276 \mathrm{kWh}$ for the system without NLP optimisation.

The further obtained results show that the system with NLP algorithm was able to reduce the annual energy deficit for the system without NLP optimisation from $376 \mathrm{kWh}$ to $1 \mathrm{kWh}$. Hence, it is concluded that the load optimisation algorithm using MATLAB NLP has helped in the optimal integration of the e-bikes solutions into the Mbita WeTu $H u b^{\prime}$ s $30 \mathrm{kWp}$ off-grid PV system at a low cost. 


\section{Conclusions}

This paper investigated the integration of e-bikes into an off-grid $30 \mathrm{kWp} \mathrm{WeTu} \mathrm{Hub}$ PV system, which is located in rural Kenya using MATLAB / Simulink / CARNOT 7.0 Toolbox. Analysis of the electricity PV production, demand, and deficit was carried out. The obtained annual PV electricity production stood at $37,785 \mathrm{kWh}$, with an annual electricity demand of $27,267 \mathrm{kWh}$ (non-optimised load profile). Since, PV system size and performance strongly depend on metrological variables such as solar irradiation, wind speed, and ambient temperature, consequently, the results obtained show an annual electricity deficit of approximately $376 \mathrm{kWh}$ for the system with non-optimised load profile. That means the system could not cover the whole electricity demand at the WeTu Hub due to the aforementioned variabilities of the PV system.

Therefore, to avoid increasing the technical size of the PV system or the use of diesel generators or grid connections for electricity deficit reduction, a load management algorithm was developed to optimally integrate the e-bikes solutions into the WeTu Hub. The load management algorithm captured the maximum amount of variable solar generation, which then sizes and schedules a finite number of devices to track available solar PV power. After the load optimisation, an annual electricity demand of 30,767 kWh was obtained which is $11 \%$ more than the non-optimised load profile of $27,267 \mathrm{kWh}$. This $11 \%$ increase $(3,500 \mathrm{kWh})$, is enough to charge 80 additional lanterns or 4 additional OpiBus batteries per day.

Author Contributions: Conceptualization, A.B., M.E., W.Z.; methodology, A.B., M.E.; resources, A.B.; writing - original draft preparation, A.B.; writing - review and editing, A.B., C.T., M.E.; visualization, A.B. ME.; supervision, M.E, W.Z

Funding: The project on which this paper is based was funded by the Deutsche Gesellschaft für Internationale Zusammenarbeit (GIZ) under contract number 81247156.

\section{Reference}

[1] Remeredzai Joseph, CLEAN TRANSPORT: Electric Boda-Bodas Launch - A Promising Day For Electric Transportation In East Africa. [Online]. Available: https://cleantechnica.com/2021/03/02/electric-boda-bodas-launch-a-promisingday-for-electric-transportation-in-east-africa/ (accessed: Mar. 10 2021).

[2] Lluc Canals Casals, Egoitz Martinez-Laserna, Beatriz Amante García, and Nerea Nieto, "Sustainability analysis of the electric vehicle use in Europe for CO2 emissions reduction," Journal of Cleaner Production, vol. 127, pp. 425437, 2016, doi: 10.1016/j.jclepro.2016.03.120.

[3] M. Åhman, "Primary energy efficiency of alternative powertrains in vehicles," Energy, vol. 26, no. 11, pp. 973-989, 2001, doi: 10.1016/S0360-5442(01)00049-4.

[4] W. Kempton, "Electric vehicles: Driving range," Nature Energy, vol. 1, no. 9, p. 16131, 2016, doi: 10.1038/nenergy.2016.131.

[5] S. Hardman, E. Shiu, and R. Steinberger-Wilckens, "Comparing high-end and low-end early adopters of battery electric vehicles," Transportation Research Part A: Policy and Practice, vol. 88, pp. 40-57, 2016, doi: 10.1016/j.tra.2016.03.010.

[6] G. Alkawsi, Y. Baashar, D. Abbas U, A. A. Alkahtani, and S. K. Tiong, Review of Renewable Energy-Based Charging Infrastructure for Electric Vehicles, 2021.

[7] A. Von Jouanne, I. Husain, A. Wallace, and A. Yokochi, "Gone with the wind: innovative hydrogen/fuel cell electric vehicle infrastructure based on wind energy sources," IEEE Industry Applications Magazine, vol. 11, no. 4, pp. 12-19, 2005, doi: 10.1109/MIA.2005.1458270.

[8] A. Shukla, K. Verma, and R. Kumar, "Impact of EV fast charging station on distribution system embedded with wind generation.," pp. 4692-4697, 2019. 
[9] C. Patrick, "Design of rural photovoltaic water pumping systems and the potential of manual array tracking for a West-African village," no. 103, pp. 288-302, 2014, doi: 10.1016/j.solener.2014.02.024.

[10]WeTu Ltd, WeTu. [Online]. Available: https://wetu.co.ke/ (accessed: 21-April-2020).

[11]O. Akindare, The World Is Leaving Africa Behind in Electric Vehicle Adoption. [Online]. Available: https:// techcabal.com/2018/08/20/the-world-is-leaving-africa-behind-in-electric-vehicle-adoption/ (accessed: Apr. 25 2019).

[12]N. Gilbert, Africa urged to use electric cars to cut air pollution. [Online]. Available: https://techcabal.com/2018/08/20/ the-world-is-leaving-africa-behind-in-electric-vehicle-adoption/ (accessed: Apr. 26 2019).

[13]SLoCaT, Transport and Climate Change Global Status Report. Partnership on Sustainable, Low Carbon Transport (SLoCaT). [Online]. Available: http://slocat.net/sites/default/files/slocat_transport-and-climate-change-2018web.pdf (accessed: Aug. 3 2019).

[14]R. Ochieng, URBAN SUSTAINABILITY REVIEW (USR) MBITA: HOMA BAY COUNTY. [Online]. Available: http:// symbiocitykenya.org/wp-content/uploads/2017/12/USR-HomabayMbita-highres-SymbioCity.pdf (accessed: 22Nov-2019).

[15]A. Kumar, Understanding the Emerging Role of Motorcycles in African Cities : A Political Economy Perspective. SubSaharan Africa Transport Policy Program (SSATP) discussion paper. [Online]. Available: https:// openknowledge.worldbank.org/handle/10986/17804 (accessed: Nov. 27 2019).

[16]R. Gammon and M. Sallah, "Preliminary Findings From a Pilot Study of Electric Vehicle Recharging From a StandAlone Solar Minigrid," Frontiers in Energy Research, vol. 8, p. 374, 2021, doi: 10.3389/fenrg.2020.563498.

[17]L. S. A. Grande, I. Yahyaoui, and S. A. Gómez, "Energetic, economic and environmental viability of off-grid PVBESS for charging electric vehicles: Case study of Spain," Sustainable Cities and Society, vol. 37, pp. 519-529, 2018, doi: 10.1016/j.scs.2017.12.009.

[18]O. Hafez and K. Bhattacharya, "Optimal design of electric vehicle charging stations considering various energy resources," Renewable Energy, vol. 107, pp. 576-589, 2017, doi: 10.1016/j.renene.2017.01.066.

[19]O. Ekren, C. Hakan Canbaz, and Ç. B. Güvel, "Sizing of a solar-wind hybrid electric vehicle charging station by using HOMER software," Journal of Cleaner Production, vol. 279, p. 123615, 2021, doi: 10.1016/j.jclepro.2020.123615.

[20]X. Liang and Tanyi, E. and Zou, X., "Charging electric cars from solar energy," 2016. [Online]. Available: http:// www.diva-portal.org/smash/record.jsf?pid=diva2\%3A935136\&dswid=-2621

[21]Mueller, O.M. and Mueller, E.K., “Off-grid, low-cost, electrical sun-car system for developing countries,” IEEE Global Humanitarian Technology Conference (GHTC 2014), vol. 34, no. 1, pp. 14-17, 2014.

[22]R. Gautham, M. Chandra, V. Peter, and V. Tim, “Solar Powered E-Bike Charging Station with AC, DC and Contactless Charging," 20th European Conference on Power Electronics and Applications EPE'18 ECCE Europe, pp. 110, 2018.

[23]Y.-M. Wi, J.-U. Lee, and S.-K. Joo, “Electric vehicle charging method for smart homes/buildings with a photovoltaic system," IEEE Trans. Consumer Electron., vol. 59, no. 2, pp. 323-328, 2013, doi: 10.1109/TCE.2013.6531113.

[24]G. R. Chandra Mouli, P. Bauer, and M. Zeman, "System design for a solar powered electric vehicle charging station for workplaces," Applied Energy, vol. 168, pp. 434-443, 2016, doi: 10.1016/j.apenergy.2016.01.110.

[25]A. R. Bhatti, Z. Salam, and R. H. Ashique, “Electric Vehicle Charging Using Photovoltaic based Microgrid for Remote Islands," Energy Procedia, vol. 103, pp. 213-218, 2016, doi: 10.1016/j.egypro.2016.11.275.

[26]S. Bimenyimana et al., "Integration of Microgrids and Electric Vehicle Technologies in the National Grid as the Key Enabler to the Sustainable Development for Rwanda," International Journal of Photoenergy, vol. 2021, p. 9928551, 2021, doi: 10.1155/2021/9928551. 
[27]E. Park and S. J. Kwon, "Renewable electricity generation systems for electric-powered taxis: The case of Daejeon metropolitan city," Renewable and Sustainable Energy Reviews, vol. 58, pp. 1466-1474, 2016, doi: 10.1016/j.rser.2015.12.308.

[28]P.-E. Dziadek, W. Feucht, A. Mittnacht, H.-G Kula, and H. Frank, “Eco-friendly application of EVs for home-towork and home-to-education transports," 2013 IEEE International Conference on Industrial Technology (ICIT), pp. 705-709, 2013.

[29]Siemens Stiftung, WeTu Social business model with new technologies. [Online]. Available: https://www.siemensstiftung.org/en/projects/wetu/ (accessed: 02-August-2020).

[30]Simiyu Sitati, REPORT ON THE MEASUREMENT CAMPAIGN E-MOBILITY FOR RURAL AFRICA. MOI University, Kenya.

[31]Knights Energy, Mbita Solar Hub Engineering Documentation.

[32]HOPPECKE, Accumulatorenwerke HOPPECKE Carl Zoellner \& Sohn GmbH OPzS solar.power. Vented lead-acid battery for cyclic applications. [Online]. Available: https://www.europe-solarstore.com/download/hoppecke/opzs/OPzS_ solar.power_en.pdf (accessed: 21-Sep-2019).

[33]SMA Solar Technology AG, Off-Grid Inverter SUNNY ISLAND 5048. Technical description. [Online]. Available: https://rexel-cdn.com/Products/SMA/SI5048U.pdf?i=216B015B-AA7E-4040-8D56-CE07DEC2145F (accessed: 05February-2020).

[34]SMA Solar Technology AG, Operating manual SUNNY TRIPOWER 15000TL / 20000TL / 25000TL. [Online]. Available: https://www.sma.de/en/products/solarinverters/sunny-tripower-15000tl-20000tl-25000tl.html (accessed: 04-April-2020).

[35]SolarWorld, Sunmodule SW 220 Poly. [Online]. Available: http://www.iwr.de/solarworld/SWM_220_poly_05-8.pdf (accessed: 10-Sep-2019).

[36]Bosch Solar, Powerful performance - high stability. Bosch Solar Module c-Si M 60 EU30117. [Online]. Available: https:// www.solarchoice.net.au/wp-content/uploads/Bosch-Solar-Module-c-Si-M-60-Australia.pdf (accessed: 05-April2020).

[37]SERC - Strathmore University Energy Research Centre, WeHub Technical Performance Assessment Report. Kenya.

[38]Time and date, Moon Phases 2020 - Lunar Calendar for Mbita, Homa Bay, Kenya. [Online]. Available: https:// www.timeanddate.com/moon/phases/@187028?year=2020 (accessed: 01-Jan-2021).

[39]Meteotest AG, Meteonorm Software Worldwide irradiation data. [Online]. Available: https://meteonorm.com/en/ (accessed: 04-April-2020).

[40]Arnold Wohlfeil, CARNOT Toolbox. [Online]. Available: https://nl.mathworks.com/matlabcentral/fileexchange/ 68890-carnot-toolbox (accessed: Feb. 8 2020).

[41]A. Bugaje, M. Ehrenwirth, C. Trinkl, and W. Zörner, "Investigating the Performance of Rural Off-Grid Photovoltaic System with Electric-Mobility Solutions: A Case Study Based on Kenya," Journal of Sustainable Development of Energy, Water and Environment Systems, N/A, N/A, p. 0, 2021, doi: 10.13044/j.sdewes.d9.0391.

[42]A. K. Shukla, K. Sudhakar, and P. Baredar, “Design, simulation and economic analysis of standalone roof top solar PV system in India," vol. 136, pp. 437-449, 2016, doi: 10.1016/j.solener.2016.07.009.

[43]M. Weiss, K. C. Cloos, and E. Helmers, "Energy efficiency trade-offs in small to large electric vehicles," Environmental Sciences Europe, vol. 32, no. 1, p. 46, 2020, doi: 10.1186/s12302-020-00307-8.

[44]Siemens Stiftung, E-Mobility Solutions for Rural Sub-Saharan Africa: Leveraging Economic, Social and Environmental Change. [Online]. Available: https://www.siemens-stiftung.org/wp-content/uploads/medien/publikationen/ publication-emobility-emobilitysolutionsforruralsubsaharanafrica-siemensstiftung.pdf (accessed: 04-April-2021). 